\title{
Target-Specific PET Probes for Neurodegenerative Disorders Related to Dementia
}

\author{
Ahmadul Kadir ${ }^{1}$ and Agneta Nordberg ${ }^{1,2}$ \\ ${ }^{1}$ Division of Alzheimer Neurobiology, Department of Neurobiology, Care Sciences and Society, Karolinska Institutet, Karolinska \\ University Hospital Huddinge, Stockholm, Sweden; and ${ }^{2}$ Department of Geriatric Medicine, Karolinska University Hospital \\ Huddinge, Stockholm, Sweden
}

\begin{abstract}
Learning Objectives: On successful completion of this activity, participants should be able to describe (1) different PET tracers for measuring functional activity, neurotransmitter systems, and pathologic markers in the brain of patients with dementia; (2) how to use different PET tracers to study the typical pattern of changes in different types of dementia; and (3) how to discriminate between the different dementia disorders using PET in clinical practice.

Financial Disclosure: The authors of this article have indicated that they serve as board members, officers, or trustees of Elan, Pfizer, GlaxoSmithKline, Novartis, Lundbeck Inc., and GE Healthcare; are consultants or advisors for AstraZeneca; are meeting participants or lecturers for Novartis and Eli Lilly; and are involved with scientific studies or trials by Novartis, GlaxoSmithKline, Wyeth, and TorryPines Therapeutics, Inc. No other potential conflict of interest relevant to this article was reported.

CME Credit: SNM is accredited by the Accreditation Council for Continuing Medical Education (ACCME) to sponsor continuing education for physicians. SNM designates each JNM continuing education article for a maximum of 1.0 AMA PRA Category 1 Credit. Physicians should claim only credit commensurate with the extent of their participation in the activity.

For CE credit, participants can access this activity through the SNM Web site (http://www.snm.org/ce_online) through September 2011.
\end{abstract}

Dementia is a highly prevalent problem causing considerable disability and mortality and exacting great costs to individuals, their families, and society. The 4 most common neurodegenerative disorders that cause dementia-Alzheimer disease, frontotemporal dementia, dementia with Lewy bodies, and dementia in Parkinson disease-have different underlying etiologies and pathogenetic mechanisms. There is a great need for early diagnostic markers; functional brain imaging may therefore assist in the detection and differential diagnosis of dementia due to neurodegenerative diseases. Functional imaging such as PET allows in vivo imaging of functional brain activity indicating cerebral blood flow and cerebral glucose metabolism, and PET allows imaging of neurotransmitter activity, including that of the cholinergic, dopaminergic, and serotonergic systems. New PET neuroimaging tracers are being developed for detecting pathologic parameters such as amyloid plaque and microglial activity. The development of molecular imaging is important for early diagnosis of dementia, selection of patients for therapies, and evaluation of therapies.

Key Words: PET; dementia; neurodegenerative disorders; functional activity; neurotransmitter pathology

J Nucl Med 2010; 51:1418-1430

DOI: 10.2967/jnumed.110.077164

Received Nov. 4, 2008; revision accepted Apr. 20, 2010.

For correspondence or reprints contact: Agneta Nordberg, Division of Alzheimer Neurobiology, Department of Neurobiology, Care Sciences and Society, Karolinska Institutet, Karolinska University Hospital Huddinge, Novum Floor-5, S-14186 Stockholm, Sweden.

E-mail: Agneta.K.Nordberg@ki.se

COPYRIGHT @ 2010 by the Society of Nuclear Medicine, Inc.
$\mathbf{N}$ eurodegenerative diseases are a large group of neurologic disorders. By definition, a neurodegenerative disease is one with selective and progressive loss of specific populations of neurons for reasons that in most cases remain unknown. The most common neurodegenerative disorders are associated with intracellular or extracellular deposits of abnormal proteins. The particular population of neurons that are vulnerable in each disorder determines the clinical presentation, and each disorder is defined by a specific combination of clinical, pathologic, and biochemical features. In the present review, we discuss the application of neuroimaging techniques such as PET in neurodegenerative disorders causing dementia, including Alzheimer disease (AD), frontotemporal dementia (FTD), dementia with Lewy bodies (DLB), and dementia in Parkinson disease (PDD).

$\mathrm{AD}$ is presently considered the most prevalent neurodegenerative disorder and is characterized by symptoms such as progressive loss of memory, especially episodic memory, as well as loss of other cognitive functions. Data suggest that the number of $\mathrm{AD}$ patients worldwide will increase from 26.6 million in 2006 to 106.8 million in 2050 (1). To tackle both the increasing social costs and the burden on patients and their families, great efforts are being made to develop early diagnostic markers of AD. These will enable early drug intervention and, it is hoped, lead to a cure for $\mathrm{AD}$. The neuropathologic hallmarks of $\mathrm{AD}$, including $\beta$-amyloid $(A \beta)$ deposition in extracellular plaques 
and vascular walls, the accumulation of intracellular neurofibrillary tangles (NFTs), synaptic reduction, neuronal loss, and volume loss (atrophy), probably occur many years before cognitive symptoms (2). A $\beta$ is considered a primary cause of $\mathrm{AD}$, but there is a whole cascade of other ongoing processes, including oxidative stress, inflammatory reactions, microglial activation, tau phosphorylation, and neurotransmitter impairment, leading to cognitive impairment (3). Some research criteria for the diagnosis of AD were proposed by Dubois et al. in 2007 (4). These criteria suggest the presence of early episodic memory impairment with at least one abnormal biomarker detectable by structural neuroimaging with MRI, molecular neuroimaging with PET, or cerebrospinal fluid (CSF) analysis of $A \beta$ or $\tau$-proteins. Further studies are needed to validate the clinical significance of these suggested diagnostic criteria.

FTD is a clinically, genetically, and neuropathologically heterogeneous group of diseases. The neurodegenerative process in FTD may be focal over several years, affecting either the left or the right hemisphere and involving predominantly frontal and temporal areas. The clinical symptoms of FTD are often subtle and include personality changes. Cognitive disturbances typical of FTD include attention deficits, impaired executive function, and language disturbances. Several types of neuropathologic changes underlie the clinical syndrome of FTD; all patients have in common the lobar atrophy, neuronal loss, and gliosis. Other neuropathologic processes include the presence or absence of $\tau$-protein, ubiquitin, and the predominant $\tau$-isoform, as detected by immunohistochemistry (5). Recent studies indicate that most FTD patients show brain pathology with ubiquitin-positive inclusions whereas some FTD patients show $\tau$-positive inclusions (6). Familial FTD is common, and genetic mutations have been demonstrated on chromosome 17 in the $\tau$ or progranulin genes (6).

The core features for the diagnosis of DLB are fluctuating cognition with pronounced variations in attention and alertness, recurrent visual hallucinations that are typically well formed and detailed, and spontaneous features of parkinsonism (7), as well as visual spatial problems. The pathologic diagnosis of DLB requires demonstration of cortical Lewy bodies, and its staging is determined by the density and distribution of these inclusions, though in reality this staging correlates only weakly with the severity or duration of dementia during life (8). In addition to Lewy body pathology, a significant number of patients with DLB have shown concomitant AD pathology (amyloid plaques and neurofibrillary tangles) and significant amyloid deposition in the striatum at postmortem examination (9).

Many patients with PD also develop dementia. The reported prevalence of dementia in $\mathrm{PD}$ varies from $4 \%$ to $93 \%$ and averages around $40 \%$ (10). The dementia associated with PD is characterized by impairment of short-term recall, attention, visuospatial functions, and executive functions such as decision making. In addition to manifesting cognitive impairment, PD patients can manifest personality and behavioral changes along with fluctuating confusion and visual hallucinosis. Although most clinical features of PDD overlap with DLB (11), recent guidelines defined the $1-y$ rule for distinction between them according to the onset of cognitive dysfunction in relation to extrapyramidal motor symptoms $(7,12)$. Pathologically, PD is characterized by the presence of cortical Lewy bodies and degeneration of subcortical nuclei including the dopaminergic medial substantia nigra, the cholinergic nucleus basalis of Meynert, the noradrenergic locus ceruleus, and serotonergic median raphe, along with other brain stem nuclei. The presence of $\mathrm{A} \beta$ has occasionally been reported in idiopathic PD, though this is more commonly a feature in PD patients who have developed later dementia (PDD) (13).

Mild cognitive impairment (MCI) is considered a transitional stage between normal aging and dementia disorder, especially in AD. MCI is a heterogeneous syndrome characterized by memory impairment or impairment in another cognitive domain but with preserved activities of daily living (14). Amnestic MCI ( 30\% of MCI patients) refers to the subtype that involves impairment primarily of the memory component, either alone (single-domain) or in conjunction with impairment of other cognitive domains (multiple-domain). Clinical cohorts suggest that about $12 \%$ of patients with the amnestic form of MCI progress to $\mathrm{AD}$ each year, and up to $80 \%$ have progressed to $\mathrm{AD}$ after 6 y (15). However, some MCI patients are likely to develop other form of dementia such as FTD or DLB (16).

Pathologic studies have shown that it is possible to find mixed dementia (i.e., AD plus vascular lesions) in elderly people (17). Studies also have suggested that AD and vascular lesions may interact with each other to increase the probability of dementia $(17,18)$. However, the clinical features typical of $\mathrm{AD}$ (e.g., progressive cognitive decline) may also be found in vascular dementia.

Quantitative imaging of functional and pathologic processes in the living human brain has become feasible through the development of PET techniques. PET is a noninvasive tomographic method for imaging the regional distribution of radioactive tracers. PET may facilitate early diagnosis, differential diagnosis, and evaluation of drug treatment in patients with dementia. PET tracers that have been developed for studies of functional activity, neurotransmitter activity, and pathologic processes in different dementia disorders (Tables 1 and 2) are reviewed in this paper.

\section{BRAIN GLUCOSE METABOLISM}

The cerebral metabolic rate of glucose (CMRglc) in humans is studied by means of ${ }^{18} \mathrm{~F}-\mathrm{FDG}$ and may reflect synaptic activity in different areas of the brain. Because glucose is the main source of energy in the nonstarvation state of the brain, a PET scan shows how well brain cells are using glucose and how the neurons are firing.

${ }^{18}$ F-FDG PET has been used for studies of metabolic patterns in different dementia disorders (19). ${ }^{18} \mathrm{~F}-\mathrm{FDG}$ 
TABLE 1. PET Ligands Used to Measure Functional Activity and Neurotransmitters in Patients with Different Dementias

\begin{tabular}{|c|c|c|}
\hline Parameter & PET radioligand & Assessment \\
\hline Functional activity & $\begin{array}{l}{ }^{11} \mathrm{C}-\text { butanol } \\
{ }^{15} \mathrm{O}-\mathrm{H}_{2} \mathrm{O} \\
{ }^{18} \mathrm{~F}-\mathrm{FDG}\end{array}$ & $\begin{array}{l}\text { Cerebral blood flow } \\
\text { Cerebral blood flow } \\
\text { Glucose use }\end{array}$ \\
\hline \multicolumn{3}{|l|}{ Neurotransmitters } \\
\hline \multirow[t]{8}{*}{ Acetylcholine } & ${ }^{11} \mathrm{C}-\mathrm{PMP}$ & Acetylcholinesterase activity \\
\hline & ${ }^{11} \mathrm{C}-\mathrm{MP} 4 \mathrm{~A}$ & Acetylcholinesterase activity \\
\hline & ${ }^{11} \mathrm{C}$-methyl-4-piperidinyl- $N$-butyrate & Butyrocholinesterase activity \\
\hline & ${ }^{11} \mathrm{C}$-nicotine & Nicotinic receptors \\
\hline & ${ }^{18}$ F-fluoro-A-85380 & Nicotinic receptors \\
\hline & ${ }^{11} \mathrm{C}$-benztropine & Muscarinic receptors \\
\hline & ${ }^{11} \mathrm{C}-\mathrm{N}$-methyl-4-piperidyl benzilate & Muscarinic receptors \\
\hline & ${ }^{18} \mathrm{~F}$-fluoropropyl-thiadiazolyltetrahydro-1-methylpyridine & Muscarinic receptors \\
\hline \multirow[t]{2}{*}{ Serotonin } & ${ }^{18} \mathrm{~F}-\mathrm{MPPF}$ & $5-\mathrm{HT}_{1 \mathrm{~A}}$ receptors \\
\hline & ${ }^{18} \mathrm{~F}$-altanserin & $5-\mathrm{HT}_{2 \mathrm{~A}}$ receptors \\
\hline \multirow[t]{5}{*}{ Dopamine } & ${ }^{18} \mathrm{~F}$-fluorodopa & Dopamine synthesis and vesicular storage \\
\hline & ${ }^{11} \mathrm{C}-\beta-\mathrm{CFT} /{ }^{18} \mathrm{~F}-\beta-\mathrm{CFT}$ & Dopamine reuptake site \\
\hline & ${ }^{11} \mathrm{C}-\mathrm{SCH}-23390$ & Dopamine $\left(D_{1}\right)$ receptors \\
\hline & ${ }^{11} \mathrm{C}$-raclopride & Dopamine $\left(D_{2}\right)$ receptors \\
\hline & ${ }^{11} \mathrm{C}-\mathrm{DTBZ}$ & Monoamine transporter \\
\hline
\end{tabular}

PET shows that in $\mathrm{AD}$, metabolic deficits are present in the neocortical association areas, with sparing of the basal ganglia, thalamus, cerebellum, primary sensory motor cortex, and visual cortex (20). Figure $1 \mathrm{~A}$ illustrates a typical ${ }^{18} \mathrm{~F}$ FDG PET scan of cerebral glucose metabolism in a patient with AD. PET of glucose metabolism in AD patients shows a consistent pattern of reduced glucose metabolism in the precuneus, posterior cingulate cortex, and parietotemporal regions and extending to the frontal cortex along with advancing disease $(21,22) .{ }^{15} \mathrm{O}$-labeled $\mathrm{H}_{2} \mathrm{O}$ is a PET tracer used to study cerebral blood flow and has been used in dementia research. The regions of reduced cerebral blood flow in $\mathrm{AD}$ are the same as the regions of reduced regional CMRglc in AD (23). A limitation of the ${ }^{15} \mathrm{O}-\mathrm{H}_{2} \mathrm{O}$ PET method is that it can be performed only in a PET center

\begin{tabular}{|c|c|}
\hline Parameter & PET radioligand \\
\hline Amyloid plaque & $\begin{array}{l}{ }^{18} \mathrm{~F}-\mathrm{FDDNP} \\
{ }^{11} \mathrm{C}-\mathrm{PIB} \\
{ }^{18} \mathrm{~F}-\mathrm{BAY}-94-9172 \\
{ }^{11} \mathrm{C}-\mathrm{BF}-227 \\
{ }^{11} \mathrm{C}-\mathrm{SB}-13 \\
{ }^{18} \mathrm{~F}-\mathrm{AV}-45 \\
{ }^{11} \mathrm{C}-\mathrm{AZD}-2184\end{array}$ \\
\hline$\tau$-protein & ${ }^{18} \mathrm{~F}-\mathrm{FDDNP}$ \\
\hline Microglia & $\begin{array}{l}{ }^{11} \mathrm{C}-(R)-\mathrm{PK} 11195 \\
{ }^{11} \mathrm{C}-\mathrm{DAA} 1106\end{array}$ \\
\hline Astrocytes & ${ }^{11} \mathrm{C}-\mathrm{DED}$ \\
\hline \multicolumn{2}{|c|}{$\begin{array}{l}{ }^{11} \mathrm{C}-\mathrm{SB}-13={ }^{11} \mathrm{C}-4-N \text {-methylamino- } 4^{\prime}-\text { hydroxystilbene; }{ }^{18} \mathrm{~F}- \\
\text { AV-45 }=(E)-4-(2-(6-(2-(2-(2-18 \mathrm{~F}-\text { fluoroethoxy }) \text { ethoxy }) \text { ethoxy }) \\
\text { pyridin-3-yl)vinyl)- } N \text {-methyl benzenamine. }\end{array}$} \\
\hline
\end{tabular}

with a cyclotron unit because of the short half-life of ${ }^{15} \mathrm{O}$ (2 min).

Two brain regions, the anterior parahippocampal gyrus and the hippocampus, have shown significantly lower CMRglc in MCI patients than in healthy controls (24). In addition, CMRglc in the anterior parahippocampal gyrus correctly classified $85 \%$ of healthy controls and MCI patients (24). Reduction in CMRglc in the posterior cingulate cortex was observed in patients with early $\mathrm{AD}(25)$. In another study, hypometabolism of the posterior cingulate and temporoparietal cortex was observed in MCI patients, when compared with controls. Progression of some of these patients to probable AD showed additional bilateral hypometabolism in prefrontal areas, with further reduction in the posterior cingulate and parietal cortex, but no such changes in MCI patients who remained stable (26). In MCI patients, delayed episodic memory performance significantly correlated with hypometabolism in the frontal cortex (27). Comparison between the 2 MCI subtypes (amnestic and nonamnestic) showed temporal lobe hypometabolism in amnestic MCI subjects, possibly reflecting the conversion to $\operatorname{AD}(28,29)$. Glucose metabolism is a sensitive measure of change in cognition and functional ability both in $\mathrm{AD}$ and in MCI and has value in predicting future cognitive decline (30).

Longitudinal studies have demonstrated a significant reduction of CMRglc in the frontal, parietal, temporal, and posterior cingulate regions in $\mathrm{AD}$ subjects, which contrasts with the absence of significant decline in healthy control subjects (31). During disease progression, glucose metabolism continues to decline and is associated with worsening scores in cognitive tests (32). This observation indicates that ${ }^{18} \mathrm{~F}-\mathrm{FDG}$ PET can serve as a biomarker in therapeutic trials. Indeed, several cholinesterase inhibitors such as donepezil (33), rivastigmine $(34,35)$, galantamine 


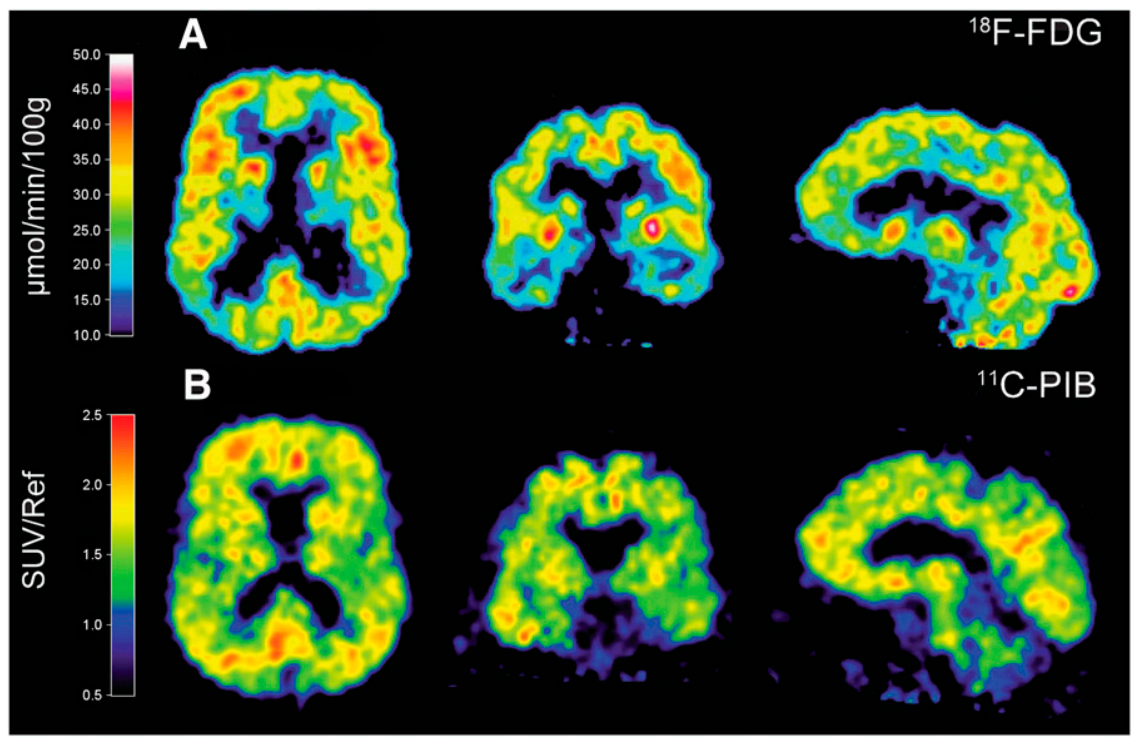

FIGURE 1. PET illustrating cerebral glucose metabolism as assessed by ${ }^{18} \mathrm{~F}-\mathrm{FDG}$, showing reduction of glucose metabolism in parietotemporal region (A) whereas amyloid plaque burden as assessed by ${ }^{11} \mathrm{C}$-PIB shows high PIB retention in large areas of brain $(B)$ in 63-y-old patient with AD. ${ }^{18} \mathrm{~F}-\mathrm{FDG}$ image was derived from Patlak analysis. ${ }^{11} \mathrm{C}-\mathrm{PIB}$ images were derived from summations of SUVs over 40-60 min and normalized with reference region cerebellum. Scale indicates high (red) to low (blue) tracer uptake or binding. Images represent horizontal, coronal, and sagittal sections.

(36), and phenserine (37) have shown positive effects on CMRglc in patients with mild to moderate AD.

Functional changes in the brain can be detected in subjects at risk of AD. Asymptomatic carriers of mutations of either the amyloid precursor protein gene or the presenilin gene have been shown to have progressive parietotemporal hypometabolism resembling the pattern seen in clinical AD $(38,39)$. The apolipoprotein E (APOE) $\varepsilon 4$ allele is a susceptibility gene that generally is overrepresented in patients with AD. Significantly lower glucose metabolism in AD-related brain regions has been reported in cognitively normal $\varepsilon 4$ carriers than in non- $\varepsilon 4$ allele carriers (40-42). Furthermore, a relationship between reduced CMRglc in AD-vulnerable brain regions and a maternal family history of $\mathrm{AD}$ in cognitively normal individuals has been observed (43).

Characteristic ${ }^{18} \mathrm{~F}$-FDG PET metabolic patterns are observed in patients with other types of dementia. In DLB, a deficit in CMRglc has been observed in the temporal, parietal, occipital, and cerebral cortices $(44,45)$. The hallucinations that are a clinical symptom of DLB are likely a correlate of a reduction of CMRglc in the primary visual cortex (46); in contrast, metabolic activity in the primary visual cortex is usually well preserved in AD. In another PET study, significantly lower CMRglc was revealed for the visual cortex (Brodmann areas 17-19) in the DLB group than the $\mathrm{AD}$ group, but no differences were found in other regions commonly affected in $\mathrm{AD}$, including the posterior cingulate, superior parietal lobe, lateral temporal lobe, and prefrontal region (47). Delusions are frequent in DLB, and a significant relative hypometabolism of the right prefrontal cortex was found in the DLB patients with delusions (48). For differential diagnosis between AD and DLB,

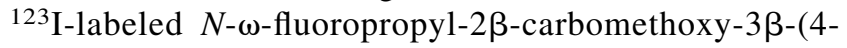
iodophenyl)nortropane) (FP-CIT), reflecting dopamine uptake sites, might be preferable to ${ }^{18} \mathrm{~F}-\mathrm{FDG}$ for discrim- ination (49). An improvement in diagnostic accuracy between DLB and AD, with a sensitivity of $78 \%$ and specificity of $94 \%$, has been reported using ${ }^{123}$ I-FP-CIT (50).

Patients with FTD show hypometabolism mainly in the frontal, anterior temporal lobe (51). The regional pattern of predominantly frontal impairment usually allows clear distinction from $\mathrm{AD}$, although there may be some overlap because $\mathrm{AD}$ can involve frontal regions and FTD may not spare the temporoparietal cortex (21). A series of 45 patients with a pathologically confirmed diagnosis showed that ${ }^{18} \mathrm{~F}$-FDG PET can discriminate FTD from AD with more than $85 \%$ sensitivity and specificity (52). It might be difficult to discriminate between FTD and AD using ${ }^{18}$ F-FDG PET. Structural imaging adds value because, commonly, marked atrophy is observed in the frontal and anterior temporal lobe (often asymmetric) (6).

In PDD, reduced CMRglc has been observed in the parietal, frontal, lateral temporal, and visual cortices (53); however, PET of dopamine receptors is more specific for the disease.

Imaging of CMRglc with ${ }^{18}$ F-FDG PET is highly sensitive and specific for early differential diagnosis of the forms of dementia. In the United States, Medicare (the governmentadministered program of health insurance) covers ${ }^{18} \mathrm{~F}-\mathrm{FDG}$ PET for the discrimination of AD from FTD.

\section{IMAGING OF NEUROTRANSMITTER ACTIVITY}

PET tracer studies on neurotransmitter systems in dementias may increase the understanding of the pathophysiologic mechanisms of different disorders and thereby improve diagnostic accuracy, because in certain diseases a particular neurotransmitter system is predominantly involved. The major transmitter systems that are impaired in dementias are the cholinergic, serotonergic, dopaminergic, glutaminergic, and noradrenergic systems. $\mathrm{AD}$ is characterized by impairment of the neocortical cholinergic 
system (54), whereas in PD and related dementias, major disturbances exist in the dopaminergic systems but the cholinergic system may also be impaired (55). Less is known about neurotransmitter changes in FTD, but a selective vulnerability of serotonergic neurons was recently observed (56). The PET tracers that have been developed for neurotransmitter systems and applied to studies of patients with various dementias are discussed in this section.

\section{Cholinergic Neurotransmission}

Acetylcholinesterase Activity. The most important degrading enzyme for acetylcholine in the human cortex is acetylcholinesterase, which is present in cholinergic axons. In the cortex, acetylcholinesterase is present in axons innervating it from the basal forebrain (57). There also is acetylcholinesterase in intrinsic cortical neurons, and low levels of acetylcholinesterase are probably present in the noncholinergic structures postsynaptic to the nucleus basalis innervation (58). As the cholinergic axons degenerate, acetylcholinesterase activity is reduced. The labeled analogs of acetylcholine that are substrates for acetylcholinesterase can be used for measuring and imaging its activity in vivo. Thus, the PET tracers $N-{ }^{11} \mathrm{C}$-methylpiperidine-4-yl propionate $\left({ }^{11} \mathrm{C}-\mathrm{PMP}\right)$ and $N-{ }^{11} \mathrm{C}$-methylpiperidyl-4-yl acetate $\left({ }^{11} \mathrm{C}-\mathrm{MP} 4 \mathrm{~A}\right)$ have been used to measure acetylcholinesterase activity $(59,60)$, and a decline was found in AD patients, compared with healthy controls (21). Eggers et al. (61) studied ${ }^{11} \mathrm{C}-\mathrm{MP} 4 \mathrm{~A}$ imaging in AD patients with different APOE $\varepsilon 4$ genotypes and found that acetylcholinesterase activity was lower in AD patients who were not APOE $\varepsilon 4$ allele carriers than in those who had the APOE $\varepsilon 4$ allele. These results indicate that cortical acetylcholinesterase activity is relatively well preserved in APOE $\varepsilon 4$ carriers, either by preservation of its cellular expression or as acetylcholinesterase activity in amyloid plaques. A significant correlation between attention tests such as digit span and cortical acetylcholinesterase activity, measured by ${ }^{11} \mathrm{C}$ PMP, has been described in AD patients (62). Reduction in acetylcholinesterase activity has also been reported in MCI patients (63), especially in MCI patients who later convert to $\mathrm{AD}$ (64), suggesting that acetylcholinesterase changes might precede the development of clinical AD. The PET technique has also been used to measure druginduced acetylcholinesterase inhibition in AD patients, which for all currently available cholinesterase inhibitors at the standard clinical dose ranges from $30 \%$ to $40 \%$ (6567). Figure 2 illustrates the cortical acetylcholinesterase inhibition measured by ${ }^{11} \mathrm{C}-\mathrm{PMP}$ in a patient with mild $\mathrm{AD}$ after 3 mo of treatment with cholinesterase inhibitor galantamine, compared with baseline.

Patients with PDD have lower acetylcholinesterase activity than do AD patients (55), suggesting more severe cholinergic pathway deficits. Cortical acetylcholinesterase activity measured by ${ }^{11} \mathrm{C}$-PMP is associated with cognitive test attention in PDD patients, as in $\mathrm{AD}$ patients (68).

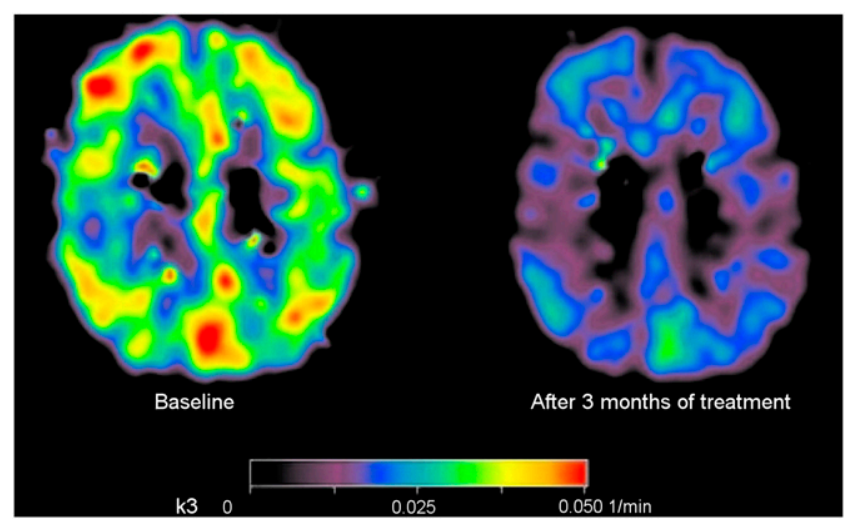

FIGURE 2. Parametric map illustrating regional cortical acetylcholinesterase activity $\left(k_{3}\right)$ before (left) and after 3 mo (right) of galantamine treatment in patient with mild $A D$ measured using ${ }^{11} \mathrm{C}-\mathrm{PMP}$. (Reprinted with permission of (67).)

Patients with DLB also show a decrease in cerebral acetylcholinesterase activity as measured by ${ }^{11} \mathrm{C}-\mathrm{MP} 4 \mathrm{~A}(69)$.

Cholinergic Receptors. The main receptors for acetylcholine in the central nervous system are muscarinic and nicotinic receptors of various subtypes. The nicotinic acetylcholine receptors (nAChRs) are ligand-gated ion channels comprising 5 subunits, variously consisting of $\alpha 2-\alpha 10$ and $\beta 2-\beta 4$. The $n A C h R s$ have been implicated in a variety of central processes, such as attention, memory, and cognition. There are 3 general classes of compounds developed as PET radiotracers for nAChRs: nicotine and its derivatives, epibatidine or azetidine and their derivatives, and 3-pyridyl ether derivatives, including A-85380 (70).

PET studies using $(S)(-)-{ }^{11} \mathrm{C}$-methyl nicotine $\left({ }^{11} \mathrm{C}\right.$ nicotine) have shown a decrease in the number of cortical nAChRs in AD patients (71). Decreased cortical ${ }^{11} \mathrm{C}$ nicotine binding in $\mathrm{AD}$ patients significantly correlates with impaired cognitive function, such as impaired attention (72). When ${ }^{11} \mathrm{C}$-nicotine binding was measured by PET before and after treatment with cholinesterase inhibitors in mild-AD patients, an increased number of cortical nicotinic receptors was observed after cholinesterase inhibitor treatment. This increase significantly correlated with improvement in attention in the $\mathrm{AD}$ patients $(67,73)$.

The PET tracer $2-{ }^{18}$ F-fluoro-A-85380 has been developed to visualize a specific subtype of nAChRs, that is, $\alpha 4 \beta 2$. The major drawback with $2-{ }^{18} \mathrm{~F}$-fluoro-A-85380 is the considerably longer scanning time $(7-8 \mathrm{~h})$ it requires. Fewer clinical studies have been done with $2-{ }^{18}$ F-fluoro-A85380. Ellis et al. did not observe any significant loss of in vivo cortical nAChRs in patients with $\mathrm{AD}$, compared with age-matched healthy controls (74); however, using the same tracer, Sabri et al. showed a reduction of $\alpha 4 \beta 2$ receptors in both $\mathrm{AD}$ and $\mathrm{MCI}$ patients (75). In vivo reductions of $\alpha 4 \beta 2$ nAChR binding in the striatum and substantia nigra have also been reported in PD without dementia (76). 
Because of the extraordinarily long acquisition time required for $2{ }^{18} \mathrm{~F}$-fluoro-A-85380, the new $\alpha 4 \beta 2 \mathrm{nAChR}-$ specific radioligands (+)- and (-) $-{ }^{18} \mathrm{~F}$-norochloro-fluorohomoepibatidine have been evaluated preclinically in the porcine brain and shown 2-fold higher brain uptake and significantly shorter acquisition times (77). However, SPECT studies using ${ }^{123}$ I-5IA-85380 have shown a reduction of nAChRs in several cortical brain areas in $\mathrm{AD}$ patients (78). In patients with PD, compared with healthy volunteers, widespread reduced $2-{ }^{18}$ F-fluoro-A-85380 binding was observed, especially in the midbrain, pons, cerebellum, and several cortical areas. In addition, patients with PD and associated depression showed a pronounced reduction of $2-{ }^{18} \mathrm{~F}$-fluoro-A-85380 binding, mostly in the cingulate cortex and frontoparietooccipital cortex (79). An interesting approach is to develop PET tracers selective for $\alpha 7 \mathrm{nAChRs}$, because this receptor subtype may have a broad interaction with several neurotransmitter systems and pathologic processes in $\mathrm{AD}(80)$. Recently, the results of PET studies have suggested that ${ }^{11} \mathrm{C}-\mathrm{CHIBA}-1001$ may be a suitable radioligand for imaging $\alpha 7 \mathrm{nAChRs}$ in the human brain, providing acceptable dosimetry and pharmacologic safety at a dose required for adequate PET images (81).

Fewer PET studies have been performed to examine the muscarinic receptors in AD. Zubieta et al. studied the nonselective muscarinic receptor ligand ${ }^{11} \mathrm{C}-\mathrm{N}$-methyl-4piperidyl benzilate and did not observe any changes in AD patients (82). ${ }^{18}$ F-fluoropropyl-thiadiazolyltetrahydro1-methylpyridine, a selective tracer for M2 receptor, showed high binding in subjects who were APOE $\varepsilon 4$ carriers $(83)$.

\section{Serotonergic Neurotransmission}

Postmortem studies have shown a widespread loss of serotonin (5-hydroxytryptamine [5-HT]) subtypes 1 $\left(5-\mathrm{HT}_{1}\right)$ and $2\left(5-\mathrm{HT}_{2}\right)$ receptors in the amygdala and hippocampus of $\mathrm{AD}$ brains. In vivo PET studies have also demonstrated a loss of some subtypes of 5-HT receptors in the $\mathrm{AD}$ brain. ${ }^{18} \mathrm{~F}$-altanserin, a tracer for $5-\mathrm{HT}_{2 \mathrm{~A}}$ receptor, showed a $40 \%$ reduction in binding potential in $\mathrm{AD}$ patients, particularly in the amygdala-hippocampal complex, anterior cingulate, prefrontal cortex, lateral temporal cortex, and sensorimotor cortex, whereas a somewhat smaller loss was observed in the parietal cortex, compared with the age-matched healthy controls (84). A single study by Kristiansen et al. (85) quantified cerebral $5-\mathrm{HT}_{2 \mathrm{~A}}$ receptor density in FTD patients, using ${ }^{11} \mathrm{C}-\mathrm{MDL}$, a selective tracer for $5-\mathrm{HT}_{2}$ receptor and PET. The in vivo measurements indicated a significant reduction in $5-\mathrm{HT}_{2}$ receptor in the orbitofrontal, frontal medial, and cingulate cortices in FTD.

Hippocampal pyramidal neurons show a high concentration of $5-\mathrm{HT}_{1 \mathrm{~A}}$ receptor, and loss of these pyramidal neurons has been correlated with lower $5-\mathrm{HT}_{1 \mathrm{~A}}$ receptor densities in AD brains (86). More recent PET studies therefore have focused on changes in $5-\mathrm{HT}_{1 \mathrm{~A}}$ receptor in $\mathrm{AD}$.
PET studies using ${ }^{18} \mathrm{~F}-2^{\prime}$-methoxyphenyl-( $N$-2' -pyridinyl)$p$-fluoro-benzamidoethyipiperazine (MPPF), a selective ligand for $5-\mathrm{HT}_{1 \mathrm{~A}}$ receptor, showed diminished hippocampal binding in AD patients, whereas patients with MCI showed binding values intermediate between controls and patients with $\mathrm{AD}(86)$. The differential binding potential of ${ }^{18} \mathrm{~F}-\mathrm{MPPF}$ in the hippocampus might indicate neuronal losses and may eventually prove valuable as an early diagnostic measure even before symptoms are present, but further PET studies are needed to confirm this possibility.

\section{Dopaminergic Neurotransmission}

PET makes it possible to study aspects of dopaminergic neurotransmission such as synthesis, storage, receptor binding $\left(D_{1}\right.$ and $\left.D_{2}\right)$, reuptake, and the vesicular transporter of dopamine.

The most widely used tracer to examine dopamine synthesis and vesicular storage is $6-{ }^{18} \mathrm{~F}$-fluoro-L-dopa. A decrease in uptake of striatal $6-{ }^{18} \mathrm{~F}$-fluoro-L-dopa was observed in PD and PDD, without differences between groups (87). A deficit of dopamine synthesis similar to that in PD has been found in DLB, even at a stage when parkinsonism may not yet be prominent (88), whereas no similar abnormality is seen in patients with AD.

Compared with healthy controls, AD patients have shown a reduction in striatal dopamine $D_{1}$ receptors as measured by ${ }^{11} \mathrm{C}-\mathrm{NNC756}$ PET but not in dopamine $\mathrm{D}_{2}$ as measured by ${ }^{11} \mathrm{C}$-raclopride PET (89). However, striatal $\mathrm{D}_{2}$ receptor density, measured by ${ }^{11} \mathrm{C}$-raclopride, has been shown to be associated with severe behavioral symptoms in AD (90). Extrastriatal dopamine $\mathrm{D}_{2}$ receptors evaluated by ${ }^{11} \mathrm{C}$-labeled $(S)-N$-((1-ethyl-2-pyrrolidinyl)methyl)-5bromo-2,3-dimethoxybenzamide (FLB 457) have shown reduced binding potential in the hippocampus and temporal cortex associated with changes in memory and language performance in $\mathrm{AD}$ patients (91).

${ }^{11} \mathrm{C}$-raclopride, a well-established $\mathrm{D}_{2}$ receptor antagonist, has been used to detect signs of nigrostriatal degeneration by PET. An increase in $\mathrm{D}_{2}$ receptor binding was observed in patients with early PD (92), and a reduction in raclopride binding was observed after levodopa treatment (93). Neuroimaging of dyskinesia has been performed using ${ }^{11}$ C-labeled $R$-(+)-8-chloro-2,3,4,5-tetrahydro-3-methyl-5phenyl-1H-3-benzazepine-7-ol) (SCH-23390) ( $\mathrm{D}_{1}$ receptors) and ${ }^{11} \mathrm{C}$-raclopride ( $\mathrm{D}_{2}$ receptors) (94). No significant reduction in mean ${ }^{11} \mathrm{C}$-raclopride uptake was observed in either the putamen or the caudate nucleus in $\mathrm{AD}$ patients (89).

Striatal dopamine reuptake sites have been studied with PET in $\mathrm{AD}$ patients using the cocaine analog ${ }^{11} \mathrm{C}$-labeled $(-)$-2 $\beta$-carbomethoxy-3 $\beta$-(4-fluorophenyl)tropane ( $\beta$-CFT) as a radioligand. Compared with control subjects, AD patients showed a reduction in ${ }^{11} \mathrm{C}-\beta-\mathrm{CFT}$ uptake in the putamen and caudate nucleus (95). In PD, a decrease in ${ }^{18} \mathrm{~F}-\beta$-CFT uptake was observed in the putamen and caudate nucleus (96). ${ }^{123}$ I-FP-CIT is used in SPECT for measuring 
dopamine uptake sites and discriminates between $\mathrm{AD}$ and DLB (50).

$(+)-{ }^{11} \mathrm{C}$-dihydrotetrabenazine $\left({ }^{11} \mathrm{C}\right.$-DTBZ), a ligand that binds to monoamine transporter and is less regulated by intrasynaptic dopamine than are other dopaminergic tracers, is used as a reliable marker of dopaminergic presynaptic terminal integrity. ${ }^{11} \mathrm{C}$-DTBZ PET can be used to differentiate DLB from both PD and AD (97).

\section{PATHOLOGY MARKERS}

Recent developments in molecular imaging have opened up the possibility of imaging pathologic processes involving amyloid proteins, $\tau$-protein, activated microglia, and astrocytes.

\section{Amyloid Imaging}

Amyloid imaging in $\mathrm{AD}$ has developed rapidly in recent years. Because $A \beta$ plaque is the hallmark of $A D$ pathology, much effort has gone into developing radiotracers that allow imaging of $\mathrm{A} \beta$ plaques in vivo (98). The smallmolecule approach led to different compounds emanating from Congo red, chrysamine-G, and thioflavine to be used in amyloid imaging for PET (98). An important clinical question is whether amyloid imaging can differentiate $\mathrm{AD}$ from other forms of dementia.

${ }^{18}$ F-FDDNP. 2-(1-\{6-[(2-18 F-fluoroethyl)(methyl)amino $]-$ 2-naphthyl \}ethylidene)malononitrile ( ${ }^{18} \mathrm{~F}$-FDDNP) was the first PET tracer used in vivo for cerebral amyloid plaque (99). Increased ${ }^{18}$ F-FDDNP binding was observed in the temporal, parietal, and frontal regions of the AD brain, compared with older control subjects without cognitive impairment (99).

${ }^{18} \mathrm{~F}-\mathrm{FDDNP}$ binding in MCI patients has been reported to be intermediate between controls and AD patients (100). In addition, ${ }^{18} \mathrm{~F}$-FDDNP has been shown to bind to $\tau$-protein in AD (100), and ${ }^{18}$ F-FDDNP signal in the medial temporal lobe has been shown to be associated mainly with $\tau$-pathology whereas that in other areas of the brain is overwhelmingly related to amyloid plaque deposition (100). It has also been shown that ${ }^{18} \mathrm{~F}$-FDDNP binds to proteaseresistant prion protein in an amyloid form in postmortem tissues in Creutzfeldt-Jacob disease (101) and in vivo in a patient with prion disease (102). A negative correlation between ${ }^{18} \mathrm{~F}$-FDDNP binding and CSF A $\beta$ levels and positive correlations with CSF $\tau$-level have been observed in $\mathrm{AD}$ and MCI patients (103).

${ }^{11} C$-PIB. Pittsburgh compound B $\left({ }^{11} \mathrm{C}-\mathrm{PIB}\right)$, a derivative of thioflavin-T amyloid dye, binds with high affinity and high specificity to neuritic $A \beta$ plaques (104) but not at all to diffuse plaque and neurofibrillary tangles (105). The first ${ }^{11} \mathrm{C}$-PIB studies on humans were in Sweden in 2002. Compared with healthy controls, 16 mild-AD patients undergoing imaging with ${ }^{11} \mathrm{C}$-PIB showed significantly higher $(\times 1.9-1.5){ }^{11} \mathrm{C}-\mathrm{PIB}$ retention in the frontal, temporal, parietal, and occipital cortices and the striatum (106). Retention of ${ }^{11} \mathrm{C}$-PIB was low and similar in the pons and cerebellum of both groups (106). For ${ }^{11} \mathrm{C}-\mathrm{PIB}$, dynamic scanning quantifies binding potentials, and a relatively simple and practical way of quantifying uptake in a clinical setting is based on scans obtained approximately 60-90 min after intravenous injection of the tracer, with the cerebellum as the unaffected reference region (107). Figure 1 illustrates the high ${ }^{11} \mathrm{C}$-PIB retention in large areas of the brain, compared with the more regional selective decrease in ${ }^{18} \mathrm{~F}$ FDG uptake in a patient with mild AD. ${ }^{11} \mathrm{C}-\mathrm{PIB}$ has now been used by a large number of PET centers all over the world and consistently shows high sensitivity in detecting amyloid plaques and vascular amyloid protein in vivo $(22,108)$. In a recent study, patients undergoing brain biopsy and showing high $\mathrm{A} \beta$ aggregation in the frontal cortical biopsy specimen also revealed high cortical ${ }^{11} \mathrm{C}$ PIB uptake with PET (109). Furthermore, a significant correlation has been reported between ${ }^{11} \mathrm{C}$-PIB imaging in vivo and levels of $A \beta$ in postmortem brain tissue (110). The strong correlation between in vivo ${ }^{11} \mathrm{C}$-PIB retention and region-matched quantitative analysis of $A \beta$ plaques at autopsy supports the validity of ${ }^{11} \mathrm{C}$-PIB PET as a method for in vivo evaluation of $\mathrm{A} \beta$ plaque burden (110).

When $\mathrm{AD}$ patients underwent both ${ }^{11} \mathrm{C}$-PIB and ${ }^{18} \mathrm{~F}$ FDDNP PET, lower binding was observed with ${ }^{18} \mathrm{~F}$ FDDNP than with ${ }^{11} \mathrm{C}$-PIB (111), and ${ }^{18} \mathrm{~F}$-FDDNP showed high binding in the medial temporal lobe, probably because FDDNP binds to neurofibrillary tangles (111). Autoradiographic studies on postmortem brain tissue also confirmed lower binding of ${ }^{3} \mathrm{H}$-FDDNP than of ${ }^{3} \mathrm{H}$-PIB to AD brain tissue-10 times lower affinity for ${ }^{3} \mathrm{H}$-FDDNP than for ${ }^{3} \mathrm{H}-$ PIB to fibrillar amyloid deposition (112).

Other Amyloid PET Ligands. Several other PET ligands have also recently been tested in healthy subjects and $\mathrm{AD}$ patients. Table 2 lists the different ${ }^{11} \mathrm{C}$ - and ${ }^{18} \mathrm{~F}$-compounds that have been explored so far for amyloid imaging in demented patients. Because the half-life of ${ }^{18} \mathrm{~F}$ is longer than that of ${ }^{11} \mathrm{C},{ }^{18} \mathrm{~F}$-compounds are promising for routine use in a clinical setting. When comparing ${ }^{18} \mathrm{~F}$-florbetaben $\left({ }^{18}\right.$ F-BAY-94-9172) with ${ }^{11} \mathrm{C}-\mathrm{PIB}$, Rowe et al. (113) concluded that ${ }^{11} \mathrm{C}$-PIB seems to show a greater difference between AD patients and controls than does ${ }^{18} \mathrm{~F}-\mathrm{BAY}-94-$ 9172. ${ }^{11} \mathrm{C}-\mathrm{SV} 13$ showed a binding potential similar to that of ${ }^{11} \mathrm{C}$-PIB in a small sample of AD patients $(114) .{ }^{11} \mathrm{C}$ 2-(2-[2-dimethylaminothiazol-5-yl]ethenyl)-6-(2-[fluoro] ethoxy)benzoxazole $\left({ }^{11} \mathrm{C}-\mathrm{BF}-227\right)$ was suggested to be more sensitive for detecting amyloid plaque at later stages of $\mathrm{AD}$ disease (115), but in a recent study ${ }^{11} \mathrm{C}-\mathrm{BF}-227$ detected amyloid pathology in MCI patients (116). ${ }^{11}$ C-labeled 5-(6-\{[tert-butyl(dimethyl)silyl]oxy $\}-1,3-$ benzothiazol-2-yl)pyridin-2-amine ( $\left.{ }^{1} \mathrm{C}-\mathrm{AZD}-2184\right)$ (117), ${ }^{18} \mathrm{~F}$-flutemetamol (118), and (E)-4-(2-(6-(2-(2- $\left(2-{ }^{18} \mathrm{~F}-\right.$ fluoroethoxy)ethoxy)ethoxy)pyridin-3-yl)vinyl)- $N$-methyl benzeneamine $\left({ }^{18} \mathrm{~F}-\mathrm{AV}-45\right)(119,120)$ are new amyloid PET ligands that have been tested in AD patients.

Time Course of Amyloid and Functional Changes in AD Measured by PET. Autopsy studies on the AD brain have 
shown that $A \beta$ deposition reaches a ceiling early in the disease process and remains stable during disease progression, whereas neurofibrillary tangle formation, synaptic loss, and gliosis continue throughout the course of the illness (121). A crucial question has been whether PET amyloid imaging shows changes in amyloid load in the brain as $\mathrm{AD}$ progresses. In a 2-y follow-up study on 16 $\mathrm{AD}$ patients, ${ }^{11} \mathrm{C}$-PIB retention had not changed between baseline and the 2-y follow-up scan, suggesting an apparent plateau in amyloid load despite a decline of cerebral glucose metabolism and cognition (32). The unchanged ${ }^{11} \mathrm{C}$-PIB retention after $2 \mathrm{y}$ of follow-up may suggest a different time course for amyloid load than for changes in the functional activity in the brain (122). It is possible that the amyloid load maximizes in almost the prodromal stage of $\mathrm{AD}$, as is also supported by ${ }^{11} \mathrm{C}$-PIB PET studies on MCI patients (123). These observations are supported by other recent 1- and 2-y follow-up studies showing no significant change in ${ }^{11} \mathrm{C}$-PIB retention in $\mathrm{AD}$ patients although brain atrophy progressed significantly $(124,125)$. Even after $5 \mathrm{y}$ of follow-up, no changes in ${ }^{11} \mathrm{C}-\mathrm{PIB}$ retention were observed at the group level in AD patients (126).

Studies on ${ }^{11} \mathrm{C}-\mathrm{PIB}$ retention in MCI patients suggest that the amount of PIB binding is bimodally distributed, with one subset of MCI patients showing abundant neocortical binding (PIB-positive) and another subset showing only low, nonspecific binding (PIB-negative), indicating a lack of fibrillar amyloid deposition (127-129). Clinical follow-up studies have shown that MCI patients who converted to AD showed significantly higher ${ }^{11} \mathrm{C}$-PIB retention than did MCI nonconverters, suggesting the possibility of identifying prodromal $\mathrm{AD}$ by amyloid imaging $(123,130,131)$. Figure 3 shows ${ }^{11} \mathrm{C}-\mathrm{PIB}$ images of MCI converters and nonconverters to $\mathrm{AD}$.

An interesting question is how early a deposit of amyloid plaque can be detected in prodromal AD. Studies of

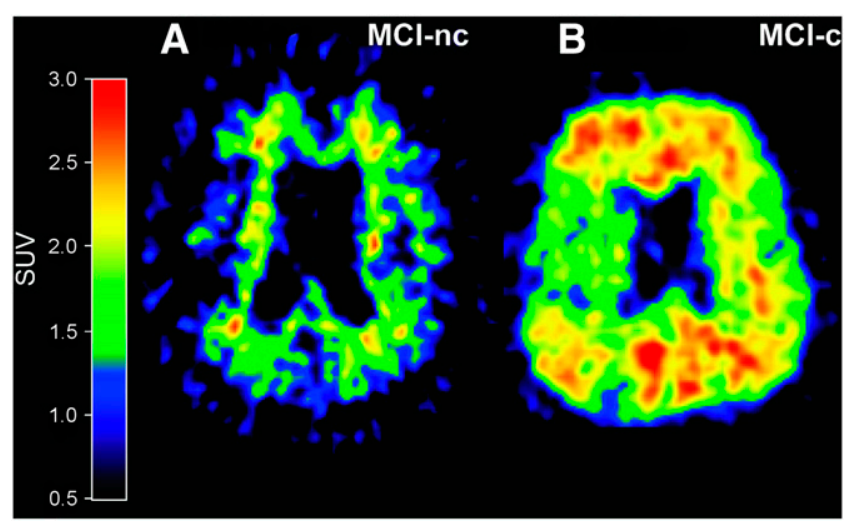

FIGURE 3. In vivo amyloid imaging as assessed by ${ }^{11} \mathrm{C}-$ $\mathrm{PIB}$ in $2 \mathrm{MCl}$ patients, one with low PIB binding (PIBnegative) who during follow-up period did not convert to $\mathrm{AD}(\mathrm{MCl}-\mathrm{nc})(\mathrm{A})$ and another with high PIB binding (PIBpositive) who later during clinical follow-up converted to $\mathrm{AD}(\mathrm{MCl}-\mathrm{C})(\mathrm{B})$. amyloid imaging in subjects at risk for developing $\mathrm{AD}$ will be of great importance. An early high PIB retention in the striatum was reported in presymptomatic carriers of presenilin-1 mutation (132). Similarly, an increased PIB uptake also in the striatum and posterior cingulate was observed in patients with amyloid precursor protein locus duplication and cerebral amyloid angiopathy (133). Compared with a sporadic-AD patient, a familial-AD patient who carried His163Tyr mutation in the presenilin-1 gene showed high PIB retention in the striatum but also in the posterior cingulate cortex and the thalamus (39). Variant$\mathrm{AD}$ patients with certain mutations of the presenilin-1 gene showed high PIB retention in the striatum (caudate nucleus and putamen), anterior and posterior cingulate gyrus, occipital cortex, and thalamus (134).

Although ${ }^{11} \mathrm{C}$-PIB seems to be more accurate than ${ }^{18} \mathrm{~F}$ FDG PET in discriminating AD (accuracies of $90 \%$ and $70 \%$, respectively) (135), a less significant correlation has been observed between episodic memory and ${ }^{11} \mathrm{C}$-PIB retention in the brains of $\mathrm{AD}$ and MCI patients $(32,123,136,137)$. The stronger correlation between cognitive performance and cerebral glucose metabolism in AD patients suggests that the decline in glucose metabolism parallels the decline in cognition during disease progression, reflecting neurodegeneration $(22,138)$. A significant negative correlation has been observed between CSF A $\beta 42$ and cortical ${ }^{11} \mathrm{C}$-PIB retention in $\mathrm{AD}$ and $\mathrm{MCI}$ patients $(139,141)$, suggesting that PET amyloid imaging and CSF A $\beta 42$ appear to be earlier markers for prodromal $\mathrm{AD}$ than are cerebral glucose metabolism and cognitive testing.

Interestingly enough, high ${ }^{11} \mathrm{C}$-PIB retention has been observed in healthy elderly control subjects $(106,142,143)$. Some ${ }^{11} \mathrm{C}$-PIB-positive elderly healthy controls have demonstrated impairment on cognitive tests (137), whereas other ${ }^{11} \mathrm{C}$-PIB-positive healthy controls have shown normal cognition (144). Longitudinal studies are needed to find out if these aged healthy subjects are in a prodromal stage of $\mathrm{AD}$ with pathologic formation of $\mathrm{A} \beta$ or whether the high amyloid load in older brains is due to slower clearance of amyloid plaque from the brain. A large longitudinal Australian study estimated that $25 \%$ of elderly individuals more than 85 y old showed a high amyloid load in the brain (145). A group of older adults who had no dementia and were PIB-positive showed greater declines in regional cerebral blood flow in certain brain areas than did PIB-negative healthy subjectsprobably a sign of decrements in neuronal function (146). In a recent longitudinal study of 159 participants, Morris et al. reported that subjects with normal cognition at baseline and ${ }^{11} \mathrm{C}$-PIB-positive PET showed a greatly increased risk of developing symptomatic $\mathrm{AD}$ in the next 2-5 y, compared with PIB-negative subjects (147).

Amyloid Imaging in FTD, $P D D$, and DLB. Amyloid plaque imaging might be important in diagnosing $\mathrm{AD}$ early and differentiating it from other forms of dementia. Generally, low cortical ${ }^{11} \mathrm{C}$-PIB retention was observed in patients with FTD $(129,148)$, as well as in PD patients 
$(129,149,150)$. Figures 4C and 4D illustrate low PIB retention in a PD patient without dementia and a patient with FTD. However, elevated ${ }^{11} \mathrm{C}$-PIB retention in the pons and mesencephalon was observed in PDD patients, compared with healthy controls (150). These findings suggest that ${ }^{11} \mathrm{C}$-PIB PET can be used to differentiate FTD, $\mathrm{PD}$, and PDD from $\mathrm{AD}$ with respect to cortical amyloid retention.

Patients with DLB have often shown high ${ }^{11} \mathrm{C}$-PIB retention in the brain (Fig. 4B) $(129,151,152)$, thought to be caused by binding to amyloid plaque and not to synuclein (153). Whether a combination of amyloid plaque and Lewy body pathology exacerbates the memory and cognitive problems in DLB is unclear, but such a combination is likely to accelerate the dementia process. It is plausible that amyloid imaging can be used to differentiate amyloidpositive DLB from amyloid-negative forms of DLB (154). Occipital PIB retention has been shown to be preferentially higher in DLB patients than in AD patients (152), and occipital hypometabolism in DLB may therefore be a consequence of this relatively higher occipital amyloid burden. At autopsy, a PIB-positive DLB patient showed PIB binding to vascular amyloid depositions (155).

High retention of this tracer has also been observed in patients with cerebral amyloid angiopathy, although the regional distribution of ${ }^{11} \mathrm{C}$-PIB in the brain seems to be somewhat different between this condition and AD (156).

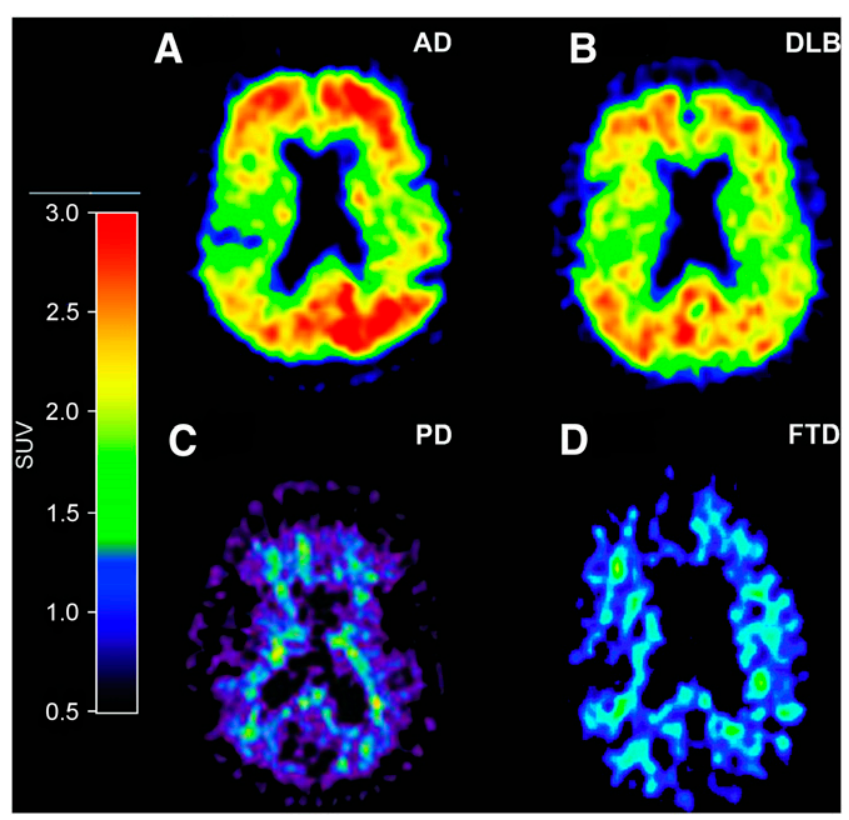

FIGURE 4. High PIB retention was observed in patient with $A D(A)$ and patient with DLB (B). In contrast, low PIB retention was observed in patient with $P D$ (not demented) (C) and in patient with FTD (D). (Part C reprinted with permission of (149); part D courtesy of Professor Henry Engler, Uppsala PET Center, Academical Hospital, Uppsala, Sweden.)
Amyloid Imaging and Drug Evaluation. Different treatment strategies to reduce the amyloid load in the brain of $\mathrm{AD}$ patients are being tested. Active and passive immunotherapy is a focus of investigation. In vivo imaging of amyloid plaque in patients undergoing antiamyloid treatment has great potential for several reasons. In vivo ${ }^{11} \mathrm{C}$ PIB imaging before the start of treatment would allow selection of patients with a demonstrably high amyloid load in the brain. Repeated studies of ${ }^{11}$ C-PIB retention during ongoing treatment would allow detection of a decrease in insoluble $A \beta$ load in the brain. In a recent study, phenserine, which inhibits formation of $\beta$-amyloid precursor protein, showed a reduction of $A \beta$ load in $A D$ brain that correlated negatively with CSF amyloid levels (37). Ongoing studies of immunization therapies are measuring ${ }^{11} \mathrm{C}$-PIB retention both before and during immunization. These studies will improve our understanding of the underlying mechanisms of antiamyloid therapy.

\section{Microglia}

The process of neurodegeneration in $\mathrm{AD}$ is associated with a local glial response within the brain parenchyma that involves activation of microglia. Activated microglia have a key role in the immune response of the brain to neuronal degeneration. Activated microglia are present at sites of aggregated $\mathrm{A} \beta$ deposition in the brains of $\mathrm{AD}$ subjects. Quantitative in vivo measurements of glial activation have used 1-[2-chlorophenyl]- $N$-methyl- $N$-[1-methylpropyl]-3isoquinoline carboxamide $\left({ }^{11} \mathrm{C}-(R)-\mathrm{PK} 11195\right)$, a specific ligand for the peripheral benzodiazepine binding receptor site. PET studies showed an increased in ${ }^{11} \mathrm{C}-(R)-$ PK11195 binding in the entorhinal, temporoparietal, and cingulate cortices in patients with mild $\mathrm{AD}$, compared with healthy control subjects (157). In a recent study, Edison et al. demonstrated high microglial activation by ${ }^{11} \mathrm{C}-(R)-\mathrm{PK} 11195$ in a group of $\mathrm{AD}$ subjects with high PIB retention. A negative correlation was reported between levels of cortical microglial activation and cognition, whereas no correlation was observed between PIB binding and ${ }^{11} \mathrm{C}-(R)-\mathrm{PK} 11195$ (158). A new approach to modeling the signal from ${ }^{11} \mathrm{C}-(R)$ PK11195 binding might, however, be needed to increase the sensitivity of the tracer, and a recent study showed that inclusion of a vascular component amplifies the binding potential in AD patients (159). PET scans with ${ }^{11} \mathrm{C}$-labeled $N$-(2,5-dimethoxybenzyl)- $N$-(5-fluoro-2phenoxyphenyl)-acetamide $\left({ }^{11} \mathrm{C}-\mathrm{DAA} 1106\right)$, a new and selective ligand for peripheral benzodiazepine binding receptor sites, have been performed on patients with $\mathrm{AD}$ and showed high binding potential in the AD brain, compared with controls (160).

Patients with PD have shown significantly increased mean levels of ${ }^{11} \mathrm{C}-(R)$-PK11195 binding in the pons, basal ganglia, and frontal and temporal cortical regions, compared with control subjects (161). Levels of microglial activation did not correlate with clinical severity or putaminal ${ }^{6-}{ }^{18} \mathrm{~F}$-fluoro-L-dopa uptake (161), indicating that widespread 
microglial activation is associated with the pathologic process in PD. Parallel changes in microglial activation by ${ }^{11} \mathrm{C}$ (R)-PK11195 and corresponding dopaminergic terminal loss by ${ }^{11} \mathrm{C}$-CFT have also been demonstrated in the affected nigrostriatal pathway in early PD (162). Elevated levels of ${ }^{11} \mathrm{C}-(R)-\mathrm{PK} 11195$ have been observed in brains of patients with FTD (163) and Huntington disease (164).

\section{Astrocytes}

Autopsy brain studies have shown an increased number of astrocytes in dementia disorders. $N$ - $\left[{ }^{11} \mathrm{C}-\right.$ methyl $]-\mathrm{L}-$ deuterodeprenyl $\left({ }^{11} \mathrm{C}\right.$-DED) binds irreversibly to the enzyme monoaminooxydase- $\mathrm{B}$, which is expressed by reactive astrocytes and can be used as a marker of reactive astrocytosis. A study of patients with Creutzfeldt-Jacob disease showed an increase in ${ }^{11} \mathrm{C}$-DED binding accompanied by a decrease in cerebral glucose metabolism (165). Further studies are needed to verify the use of ${ }^{11} \mathrm{C}$-DED in neurodegenerative disorders. PET studies with ${ }^{11} \mathrm{C}-\mathrm{DED}$ in $\mathrm{AD}$ and $\mathrm{MCI}$ patients are in progress.

\section{CONCLUSION}

Clinical, pathologic, and genetic evidence indicates that the neurodegenerative dementias have different underlying etiologies and pathogenetic mechanisms. PET allows the measurement of pathologic processes such as those involving amyloid plaque, reactive microglia, and astrocytes, as well as neurodegeneration reflected by declining cerebral glucose metabolism and impaired neurotransmitters. Accurate and early differentiation of dementias will become increasingly important as new therapies are introduced. Differential diagnosis by standard clinical criteria has limited accuracy. However, the rapid development of the field of molecular imaging is presently promising. PET offers the potential to increase diagnostic accuracy. Treatment approaches probably will be different for each major form of degenerative dementia.

Recently, reliable PET tracers for assessing the $A \beta$ burden in the brain have been introduced, and they may have high value for early diagnosis at presymptomatic stages of $\mathrm{AD}$ and more accurate differential diagnosis from other forms of dementia. Amyloid imaging can detect the presence of amyloid plaque in the brain at prodromal stages of $\mathrm{AD}$, whereas the cerebral glucose metabolism and decline in cognition more closely follow the clinical symptoms and progression of AD. For evaluating the effect of new disease-modifying therapeutics, the combined use of brain glucose metabolism, amyloid, and microglial imaging should allow us to determine whether antiamyloid strategies clear plaques and exert therapeutic effects via stimulating or suppressing glial activation, as well as ceasing neuronal loss. It will be important to combine findings from PET with other diagnostic markers such as MRI, CSF biomarkers, and cognitive measurements to increase diagnostic accuracy.

\section{ACKNOWLEDGMENTS}

The financial support of the Swedish Research Council (project 05817), Stohne's Foundation, Foundation of Old Servants, KI Foundations, Alzheimer Foundation in Sweden, Demensfonden, Brain Foundation, Swedish Brain Power, Knut and Alice Wallenberg Foundation, and EC-FP6-project DiMI, LSHB-CT-2005-512146, is highly acknowledged. Anders Johansson and Henry Engler are thanked for providing the ${ }^{11} \mathrm{C}$-PIB PET images for PD and FTD.

\section{REFERENCES}

1. Brookmeyer R, Johnson E, Ziegler-Graha K, Arrighi HM. Forecasting the global burden of Alzheimer's disease. Alzheimers Dement. 2007;3:186-191.

2. Thal DR, Rub U, Orantes M, Braak H. Phases of A beta-deposition in the human brain and its relevance for the development of AD. Neurology. 2002;58:1791-1800.

3. Mattson MP. Pathways towards and away from Alzheimer's disease. Nature. 2004;430:631-639.

4. Dubois B, Feldman HH, Jacova C, et al. Research criteria for the diagnosis of Alzheimer's disease: revising the NINCDS-ADRDA criteria. Lancet Neurol. 2007;6:734-746.

5. McKhann GM, Albert MS, Grossman M, Miller B, Dickson D, Trojanowski JQ. Clinical and pathological diagnosis of frontotemporal dementia: report of the Work Group on Frontotemporal Dementia and Pick's Disease. Arch Neurol. 2001;58:1803-1809.

6. Arvanitakis Z. Update on frontotemporal dementia. Neurologist. 2010;16: $16-22$.

7. McKeith IG, Dickson DW, Lowe J, et al. Diagnosis and management of dementia with Lewy bodies: third report of the DLB Consortium. Neurology. 2005;65:1863-1872.

8. Harding AJ, Halliday GM. Cortical Lewy body pathology in the diagnosis of dementia. Acta Neuropathol. 2001;102:355-363.

9. Jellinger KA, Attems J. Does striatal pathology distinguish Parkinson disease with dementia and dementia with Lewy bodies? Acta Neuropathol. 2006; 112:253-260.

10. Hughes TA, Ross HF, Musa S, et al. A 10-year study of the incidence of and factors predicting dementia in Parkinson's disease. Neurology. 2000;54:15961602 .

11. Lippa CF, Duda JE, Grossman M, et al. DLB and PDD boundary issues: diagnosis, treatment, molecular pathology, and biomarkers. Neurology. 2007;68:812-819.

12. Emre M, Aarsland D, Brown R, et al. Clinical diagnostic criteria for dementia associated with Parkinson's disease. Mov Disord. 2007;22:1689-1707.

13. Mastaglia FL, Johnsen RD, Byrnes ML, Kakulas BA. Prevalence of amyloidbeta deposition in the cerebral cortex in Parkinson's disease. Mov Disord. 2003; 18:81-86

14. Petersen RC, Doody R, Kurz A, et al. Current concepts in mild cognitive impairment. Arch Neurol. 2001;58:1985-1992.

15. Petersen RC, Smith GE, Waring SC, Ivnik RJ, Tangalos EG, Kokmen E. Mild cognitive impairment: clinical characterization and outcome. Arch Neurol. 1999;56:303-308.

16. Petersen RC, Roberts RO, Knopman DS, et al. Mild cognitive impairment: ten years later. Arch Neurol. 2009;66:1447-1455.

17. Schneider JA, Arvanitakis Z, Bang W, Bennett DA. Mixed brain pathologies account for most dementia cases in community-dwelling older persons. Neurology. 2007;69:2197-2204.

18. Snowdon DA, Greiner LH, Mortimer JA, Riley KP, Greiner PA, Markesbery WR. Brain infarction and the clinical expression of Alzheimer disease. The Nun Study. JAMA. 1997;277:813-817.

19. Mosconi L, Tsui WH, Herholz K, et al. Multicenter standardized ${ }^{18}$ F-FDG PET diagnosis of mild cognitive impairment, Alzheimer's disease, and other dementias. J Nucl Med. 2008;49:390-398.

20. Silverman DH, Small GW, Phelps ME. Clinical value of neuroimaging in the diagnosis of dementia: sensitivity and specificity of regional cerebral metabolic and other parameters for early identification of Alzheimer's disease. Clin Positron Imaging. 1999;2:119-130.

21. Herholz K, Carter SF, Jones M. Positron emission tomography imaging in dementia. Br J Radiol. 2007;80(spec no 2):S160-S167. 
22. Nordberg A, Rinne JO, Kadir A, Langstrom B. The use of PET in Alzheimer disease. Nat Rev Neurol. 2010;6:78-87.

23. Ishii K, Minoshima S. PET is better than perfusion SPECT for early diagnosis of Alzheimer's disease-for. Eur J Nucl Med Mol Imaging. 2005;32:14631465 .

24. De Santi S, de Leon MJ, Rusinek H, et al. Hippocampal formation glucose metabolism and volume losses in MCI and AD. Neurobiol Aging. 2001;22: 529-539.

25. Minoshima S, Giordani B, Berent S, Frey KA, Foster NL, Kuhl DE. Metabolic reduction in the posterior cingulate cortex in very early Alzheimer's disease. Ann Neurol. 1997;42:85-94.

26. Drzezga A, Lautenschlager N, Siebner H, et al. Cerebral metabolic changes accompanying conversion of mild cognitive impairment into Alzheimer's disease: a PET follow-up study. Eur J Nucl Med Mol Imaging. 2003;30: 1104-1113.

27. Schönknecht OD, Hunt A, Toro P, Henze M, Haberkorn U, Schröder J. Neural correlates of delayed episodic memory in patients with mild cognitive impairment-a FDG PET study. Neurosci Lett. 2009;467:100-104.

28. Clerici F, Del Sole A, Chiti A, et al. Differences in hippocampal metabolism between amnestic and non-amnestic MCI subjects: automated FDG-PET image analysis. Q J Nucl Med Mol Imaging. 2009;53:646-657.

29. Morbelli S, Piccardo A, Villavecchia G, et al. Mapping brain morphological and functional conversion patterns in amnestic MCI: a voxel-based MRI and FDG-PET study. Eur J Nucl Med Mol Imaging. 2009;37:36-45.

30. Landau SM, Harvey D, Madison CM, et al. Associations between cognitive, functional, and FDG-PET measures of decline in AD and MCI. Neurobiol Aging. August 4, 2009 [Epub ahead of print].

31. Alexander GE, Chen K, Pietrini P, Rapoport SI, Reiman EM. Longitudinal PET evaluation of cerebral metabolic decline in dementia: a potential outcome measure in Alzheimer's disease treatment studies. Am J Psychiatry. 2002; 159:738-745.

32. Engler H, Forsberg A, Almkvist O, et al. Two-year follow-up of amyloid deposition in patients with Alzheimer's disease. Brain. 2006;129:2856-2866.

33. Tune L, Tiseo PJ, Ieni J, et al. Donepezil $\mathrm{HCl}$ (E2020) maintains functional brain activity in patients with Alzheimer disease: results of a 24-week, doubleblind, placebo-controlled study. Am J Geriatr Psychiatry. 2003;11:169-177.

34. Potkin SG, Anand R, Fleming K, et al. Brain metabolic and clinical effects of rivastigmine in Alzheimer's disease. Int J Neuropsychopharmacology. 2001; 4:223-230.

35. Stefanova E, Wall A, Almkvist O, et al. Longitudinal PET evaluation of cerebral glucose metabolism in rivastigmine treated patients with mild Alzheimer's disease. J Neural Transm. 2006;113:205-218.

36. Mega MS, Dinov ID, Porter V, et al. Metabolic patterns associated with the clinical response to galantamine therapy: a fludeoxyglucose F 18 positron emission tomographic study. Arch Neurol. 2005;62:721-728.

37. Kadir A, Andreasen N, Almkvist O, et al. Effect of phenserine treatment on brain functional activity and amyloid in Alzheimer's disease. Ann Neurol. 2008;63:621-631

38. Mosconi L. Brain glucose metabolism in the early and specific diagnosis of Alzheimer's disease: FDG-PET studies in MCI and AD. Eur J Nucl Med Mol Imaging. 2005;32:486-510.

39. Schöll M, Almkvist O, Axelman K, et al. Glucose metabolism and PIB binding in carriers of His163Tyr presenilin 1 mutation. Neurobiol Aging. September 29, 2009 [Epub ahead of print].

40. Mosconi L, De Santi S, Brys M, et al. Hypometabolism and altered cerebrospinal fluid markers in normal apolipoprotein E E4 carriers with subjective memory complaints. Biol Psychiatry. 2008;63:609-618.

41. Reiman EM, Chen K, Alexander GE, et al. Correlations between apolipoprotein E epsilon4 gene dose and brain-imaging measurements of regional hypometabolism. Proc Natl Acad Sci USA. 2005;102:8299-8302.

42. Small GW, Bookheimer SY, Thompson PM, et al. Current and future uses of neuroimaging for cognitively impaired patients. Lancet Neurol. 2008;7:161-172.

43. Mosconi L, Brys M, Switalski R, et al. Maternal family history of Alzheimer's disease predisposes to reduced brain glucose metabolism. Proc Natl Acad Sci USA. 2007;104:19067-19072.

44. Ishii K, Soma T, Kono AK, et al. Comparison of regional brain volume and glucose metabolism between patients with mild dementia with Lewy bodies and those with mild Alzheimer's disease. J Nucl Med. 2007;48: 704-711.

45. Small GW. Neuroimaging as a diagnostic tool in dementia with Lewy bodies. Dement Geriatr Cogn Disord. 2004;17(suppl 1):25-31.

46. Minoshima S, Foster NL, Sima AA, Frey KA, Albin RL, Kuhl DE. Alzheimer's disease versus dementia with Lewy bodies: cerebral metabolic distinction with autopsy confirmation. Ann Neurol. 2001;50:358-365.
47. Gilman S, Koeppe RA, Little R, et al. Differentiation of Alzheimer's disease from dementia with Lewy bodies utilizing positron emission tomography with $\left[{ }^{18}\right.$ F]fluorodeoxyglucose and neuropsychological testing. Exp Neurol. 2005;191 (suppl 1):S95-S103.

48. Perneczky R, Drzezga A, Boecker H, et al. Right prefrontal hypometabolism predicts delusions in dementia with Lewy bodies. Neurobiol Aging. 2009;30: 1420-1429.

49. Walker Z, Costa DC, Walker RW, et al. Differentiation of dementia with Lewy bodies from Alzheimer's disease using a dopaminergic presynaptic ligand. J Neurol Neurosurg Psychiatry. 2002;73:134-140.

50. McKeith I, O'Brien J, Walker Z, et al. Sensitivity and specificity of dopamine transporter imaging with ${ }^{123}$ I-FP-CIT SPECT in dementia with Lewy bodies: a phase III, multicentre study. Lancet Neurol. 2007;6:305-313.

51. Kanda T, Ishii K, Uemura $\mathrm{T}$, et al. Comparison of grey matter and metabolic reductions in frontotemporal dementia using FDG-PET and voxel-based morphometric MR studies. Eur J Nucl Med Mol Imaging. 2008;35:2227-2234.

52. Foster NL, Heidebrink JL, Clark CM, et al. FDG-PET improves accuracy in distinguishing frontotemporal dementia and Alzheimer's disease. Brain. 2007; 130:2616-2635.

53. Vander Borght T, Minoshima S, Giordani B, et al. Cerebral metabolic differences in Parkinson's and Alzheimer's diseases matched for dementia severity. J Nucl Med. 1997;38:797-802.

54. Davis KL, Mohs RC, Marin D, et al. Cholinergic markers in elderly patients with early signs of Alzheimer disease. JAMA. 1999;281:1401-1406.

55. Bohnen NI, Kaufer DI, Ivanco LS, et al. Cortical cholinergic function is more severely affected in parkinsonian dementia than in Alzheimer disease: an in vivo positron emission tomographic study. Arch Neurol. 2003;60:1745-1748.

56. Bowen DM, Procter AW, Mann DM, et al. Imbalance of a serotonergic system in frontotemporal dementia: implication for pharmacotherapy. Psychopharmacology (Berl). 2008;196:603-610.

57. Selden NR, Gitelman DR, Salamon-Murayama N, Parrish TB, Mesulam MM. Trajectories of cholinergic pathways within the cerebral hemispheres of the human brain. Brain. 1998;121:2249-2257.

58. Heckers S, Geula C, Mesulam MM. Acetylcholinesterase-rich pyramidal neurons in Alzheimer's disease. Neurobiol Aging. 1992;13:455-460.

59. Kilbourn MR, Snyder SE, Sherman PS, Kuhl DE. In vivo studies of acetylcholinesterase activity using a labeled substrate, N- $\left[{ }^{11} \mathrm{C}\right]$ methylpiperdin4-yl propionate ([$\left.\left.{ }^{11} \mathrm{C}\right] \mathrm{PMP}\right)$. Synapse. 1996;22:123-131.

60. Namba H, Irie $T$, Fukushi K, Iyo $M$. In vivo measurement of acetylcholinesterase activity in the brain with a radioactive acetylcholine analog. Brain Res. 1994;667:278-282.

61. Eggers C, Herholz K, Kalbe E, Heiss WD. Cortical acetylcholine esterase activity and ApoE4-genotype in Alzheimer disease. Neurosci Lett. 2006;408: 46-50.

62. Bohnen NI, Kaufer DI, Hendrickson R, et al. Cognitive correlates of alterations in acetylcholinesterase in Alzheimer's disease. Neurosci Lett. 2005;380:127132.

63. Rinne JO, Kaasinen V, Jarvenpaa T, et al. Brain acetylcholinesterase activity in mild cognitive impairment and early Alzheimer's disease. J Neurol Neurosurg Psychiatry. 2003;74:113-115.

64. Herholz K, Weisenbach S, Kalbe E, Diederich NJ, Heiss WD. Cerebral acetylcholine esterase activity in mild cognitive impairment. Neuroreport. 2005;16:1431-1434.

65. Bohnen NI, Kaufer DI, Hendrickson R, et al. Degree of inhibition of cortical acetylcholinesterase activity and cognitive effects by donepezil treatment in Alzheimer's disease. J Neurol Neurosurg Psychiatry. 2005;76:315-319.

66. Kaasinen V, Nagren K, Jarvenpaa T, et al. Regional effects of donepezil and rivastigmine on cortical acetylcholinesterase activity in Alzheimer's disease. J Clin Psychopharmacol. 2002;22:615-620.

67. Kadir A, Darreh-Shori T, Almkvist O, et al. PET imaging of the in vivo brain acetylcholinesterase activity and nicotine binding in galantamine-treated patients with AD. Neurobiol Aging. 2008;29:1204-1217.

68. Bohnen NI, Kaufer DI, Hendrickson R, et al. Cognitive correlates of cortical cholinergic denervation in Parkinson's disease and parkinsonian dementia. $J$ Neurol. 2006;253:242-247.

69. Shimada H, Hirano S, Shinotoh H, et al. Mapping of brain acetylcholinesterase alterations in Lewy body disease by PET. Neurology. 2009;73:273-278.

70. Sihver W, Langstrom B, Nordberg A. Ligands for in vivo imaging of nicotinic receptor subtypes in Alzheimer brain. Acta Neurol Scand Suppl. 2000;176: 27-33.

71. Nordberg A, Lundqvist H, Hartvig P, Lilja A, Langstrom B. Kinetic analysis of regional $(S)(-)^{11} \mathrm{C}$-nicotine binding in normal and Alzheimer brains: in vivo assessment using positron emission tomography. Alzheimer Dis Assoc Disord. 1995;9:21-27. 
72. Kadir A, Almkvist O, Wall A, Langstrom B, Nordberg A. PET imaging of cortical ${ }^{11} \mathrm{C}$-nicotine binding correlates with the cognitive function of attention in Alzheimer's disease. Psychopharmacology (Berl). 2006;188:509-520.

73. Kadir A, Darreh-Shori T, Almkvist O, Wall A, Langstrom B, Nordberg A. Changes in brain ${ }^{11} \mathrm{C}$-nicotine binding sites in patients with mild Alzheimer's disease following rivastigmine treatment as assessed by PET. Psychopharmacology (Berl). 2007;191:1005-1014.

74. Ellis JR, Villemagne VL, Nathan PJ, et al. Relationship between nicotinic receptors and cognitive function in early Alzheimer's disease: a 2-[ $\left.{ }^{18} \mathrm{~F}\right]$ fluoro-A-85380 PET study. Neurobiol Learn Mem. 2008;90:404-412.

75. Sabri O, Kendziorra K, Wolf H, Gertz HJ, Brust P. Acetylcholine receptors in dementia and mild cognitive impairment. Eur J Nucl Med Mol Imaging. 2008;35(suppl 1):S30-S45.

76. Kas A, Bottlaender M, Gallezot JD, et al. Decrease of nicotinic receptors in the nigrostriatal system in Parkinson's disease. J Cereb Blood Flow Metab. 2009;29:1601-1608.

77. Brust P, Patt JT, Deuther-Conrad W, et al. In vivo measurement of nicotinic acetylcholine receptors with $\left[{ }^{18} \mathrm{~F}\right]$ norchloro-fluoro-homoepibatidine. Synapse. 2008;62:205-218.

78. O'Brien JT, Colloby SJ, Pakrasi S, et al. Alpha4beta2 nicotinic receptor status in Alzheimer's disease using ${ }^{123}$ I-5IA-85380 single-photon-emission computed tomography. J Neurol Neurosurg Psychiatry. 2007;78:356-362.

79. Meyer PM, Strecker K, Kendziorra K, et al. Reduced alpha4beta2*-nicotinic acetylcholine receptor binding and its relationship to mild cognitive and depressive symptoms in Parkinson disease. Arch Gen Psychiatry. 2009;66: 866-877.

80. Pomper MG, Phillips E, Fan H, et al. Synthesis and biodistribution of radiolabeled alpha 7 nicotinic acetylcholine receptor ligands. J Nucl Med. 2005;46:326-334.

81. Toyohara J, Sakata M, Wu J, et al. Preclinical and the first clinical studies on $\left[{ }^{11} \mathrm{C}\right] \mathrm{CHIBA}-1001$ for mapping alpha7 nicotinic receptors by positron emission tomography. Ann Nucl Med. 2009;23:301-309.

82. Zubieta JK, Koeppe RA, Frey KA, et al. Assessment of muscarinic receptor concentrations in aging and Alzheimer disease with $\left[{ }^{11} \mathrm{C}\right] \mathrm{NMPB}$ and PET. Synapse. 2001;39:275-287.

83. Cohen RM, Podruchny TA, Bokde AL, et al. Higher in vivo muscarinic-2 receptor distribution volumes in aging subjects with an apolipoprotein E-epsilon4 allele. Synapse. 2003;49:150-156.

84. Meltzer CC, Price JC, Mathis CA, et al. PET imaging of serotonin type 2A receptors in late-life neuropsychiatric disorders. Am J Psychiatry. 1999;156: 1871-1878.

85. Kristiansen H, Elfving B, Plenge P, Pinborg LH, Gillings N, Knudsen GM. Binding characteristics of the 5-HT2A receptor antagonists altanserin and MDL 100907. Synapse. 2005;58:249-257.

86. Kepe V, Barrio JR, Huang SC, et al. Serotonin 1A receptors in the living brain of Alzheimer's disease patients. Proc Natl Acad Sci USA. 2006;103: 702-707.

87. Hilker R, Thomas AV, Klein JC, et al. Dementia in Parkinson disease: functional imaging of cholinergic and dopaminergic pathways. Neurology. 2005;65:1716-1722.

88. Hu XS, Okamura N, Arai H, et al. ${ }^{18}$ F-fluorodopa PET study of striatal dopamine uptake in the diagnosis of dementia with Lewy bodies. Neurology. 2000;55:1575-1577.

89. Kemppainen N, Ruottinen H, Nagren K, Rinne JO. PET shows that striatal dopamine D1 and D2 receptors are differentially affected in AD. Neurology. 2000;55:205-209.

90. Tanaka Y, Meguro K, Yamaguchi S, et al. Decreased striatal D2 receptor density associated with severe behavioral abnormality in Alzheimer's disease. Ann Nucl Med. 2003;17:567-573.

91. Kemppainen N, Laine M, Laakso MP, et al. Hippocampal dopamine D2 receptors correlate with memory functions in Alzheimer's disease. Eur $J$ Neurosci. 2003;18:149-154.

92. Rinne JO, Laihinen A, Ruottinen H, et al. Increased density of dopamine D2 receptors in the putamen, but not in the caudate nucleus in early Parkinson's disease: a PET study with $\left[{ }^{11}\right.$ C]raclopride. J Neurol Sci. 1995;132:156-161.

93. Tedroff J, Pedersen M, Aquilonius SM, Hartvig P, Jacobsson G, Langstrom B. Levodopa-induced changes in synaptic dopamine in patients with Parkinson's disease as measured by $\left[{ }^{11} \mathrm{C}\right]$ raclopride displacement and PET. Neurology. 1996;46:1430-1436.

94. Brooks DJ, Piccini P, Turjanski N, Samuel M. Neuroimaging of dyskinesia. Ann Neurol. 2000;47(4 suppl 1):S154-S158.

95. Rinne JO, Sahlberg N, Ruottinen H, Nagren K, Lehikoinen P. Striatal uptake of the dopamine reuptake ligand $\left[{ }^{11} \mathrm{C}\right]$ beta-CFT is reduced in Alzheimer's disease assessed by positron emission tomography. Neurology. 1998;50:152-156.
96. Rinne JO, Bergman J, Ruottinen $\mathrm{H}$, et al. Striatal uptake of a novel PET ligand, $\left[{ }^{18} \mathrm{~F}\right]$ beta-CFT, is reduced in early Parkinson's disease. Synapse. 1999;31:119-124.

97. Koeppe RA, Gilman S, Junck L, Wernette K, Frey KA. Differentiating Alzheimer's disease from dementia with Lewy bodies and Parkinson's disease with $(+)-\left[{ }^{11} \mathrm{C}\right]$ dihydrotetrabenazine positron emission tomography. Alzheimers Dement. 2008;4(1, suppl 1)S67-S76.

98. Nordberg A. PET imaging of amyloid in Alzheimer's disease. Lancet Neurol. 2004;3:519-527

99. Shoghi-Jadid K, Small GW, Agdeppa ED, et al. Localization of neurofibrillary tangles and beta-amyloid plaques in the brains of living patients with Alzheimer disease. Am J Geriatr Psychiatry. 2002;10:24-35.

100. Small GW, Kepe V, Ercoli LM, et al. PET of brain amyloid and tau in mild cognitive impairment. $N$ Engl J Med. 2006;355:2652-2663.

101. Smid LM, Vovko TD, Popovic M, et al. The 2,6-disubstituted naphthalene derivative FDDNP labeling reliably predicts Congo red birefringence of protein deposits in brain sections of selected human neurodegenerative diseases. Brain Pathol. 2006;16:124-130.

102. Boxer AL, Rabinovici GD, Kepe V, et al. Amyloid imaging in distinguishing atypical prion disease from Alzheimer disease. Neurology. 2007;69:283-290.

103. Tolboom N, van der Flier WM, Yaqub M, et al. Relationship of cerebrospinal fluid markers to ${ }^{11} \mathrm{C}-\mathrm{PiB}$ and ${ }^{18} \mathrm{~F}-\mathrm{FDDNP}$ binding. J Nucl Med. 2009;50:14641470.

104. Mathis CA, Bacskai BJ, Kajdasz ST, et al. A lipophilic thioflavin-T derivative for positron emission tomography (PET) imaging of amyloid in brain. Bioorg Med Chem Lett. 2002;12:295-298.

105. Klunk WE, Wang Y, Huang GF, et al. The binding of 2-(4'-methylaminophenyl) benzothiazole to postmortem brain homogenates is dominated by the amyloid component. J Neurosci. 2003;23:2086-2092.

106. Klunk WE, Engler H, Nordberg A, et al. Imaging brain amyloid in Alzheimer's disease with Pittsburgh compound-B. Ann Neurol. 2004;55:306-319.

107. Price JC, Klunk WE, Lopresti BJ, et al. Kinetic modeling of amyloid binding in humans using PET imaging and Pittsburgh compound-B. J Cereb Blood Flow Metab. 2005;25:1528-1547.

108. Nordberg A. Amyloid imaging in Alzheimer's disease. Neuropsychologia. 2008;46:1636-1641.

109. Leinonen V, Alafuzoff I, Aalto S, et al. Assessment of beta-amyloid in a frontal cortical brain biopsy specimen and by positron emission tomography with carbon 11-labeled Pittsburgh compound B. Arch Neurol. 2008;65:1304-1309.

110. Ikonomovic MD, Klunk WE, Abrahamson EE, et al. Post-mortem correlates of in vivo PiB-PET amyloid imaging in a typical case of Alzheimer's disease. Brain. 2008;131:1630-1645.

111. Tolboom N, Yaqub M, van der Flier WM, et al. Detection of Alzheimer pathology in vivo using both ${ }^{11} \mathrm{C}$-PIB and ${ }^{18}$ F-FDDNP PET. $J$ Nucl Med. 2009;50:191-197.

112. Thompson PW, Ye L, Morgenstern JL, et al. Interaction of the amyloid imaging tracer FDDNP with hallmark Alzheimer's disease pathologies. J Neurochem. 2009; 109:623-630.

113. Rowe CC, Ackerman U, Browne W, et al. Imaging of amyloid beta in Alzheimer's disease with ${ }^{18} \mathrm{~F}-\mathrm{BAY} 94-9172$, a novel PET tracer: proof of mechanism. Lancet Neurol. 2008;7:129-135.

114. Verhoeff NP, Wilson AA, Takeshita S, et al. In-vivo imaging of Alzheimer disease beta-amyloid with $\left[{ }^{11} \mathrm{C}\right] \mathrm{SB}-13$ PET. Am J Geriatr Psychiatry. 2004;12:584-595.

115. Kudo Y, Okamura N, Furumoto S, et al. 2-(2-[2-Dimethylaminothiazol-5-yl] ethenyl)-6-(2-[fluoro]ethoxy)benzoxazole: a novel PET agent for in vivo detection of dense amyloid plaques in Alzheimer's disease patients. $J$ Nucl Med. 2007;48:553-561.

116. Furukawa K, Okamura N, Tashiro M, et al. Amyloid PET in mild cognitive impairment and Alzheimer's disease with BF-227: comparison to FDG-PET. J Neurol. 2009;257:721-727.

117. Nyberg S, Jonhagen ME, Cselenyi Z, et al. Detection of amyloid in Alzheimer's disease with positron emission tomography using $\left[{ }^{11} \mathrm{C}\right] \mathrm{AZD} 2184$. Eur J Nucl Med Mol Imaging. 2009;36:1859-1863.

118. Nelissen N, Van Laere K, Thurfjell L, et al. Phase 1 study of the Pittsburgh compound $\mathrm{B}$ derivative ${ }^{18} \mathrm{~F}$-flutemetamol in healthy volunteers and patients with probable Alzheimer disease. J Nucl Med. 2009;50:1251-1259.

119. Choi SR, Golding G, Zhuang Z, et al. Preclinical properties of ${ }^{18} \mathrm{~F}-\mathrm{AV}-45$ : a PET agent for Abeta plaques in the brain. J Nucl Med. 2009;50:1887-1894.

120. Wong DF, Rosenberg PB, Zhou Y, et al. In vivo imaging of amyloid deposition in Alzheimer disease using the radioligand ${ }^{18} \mathrm{~F}-\mathrm{AV}-45$ (florbetapir F 18). J Nucl Med. 2010;51:913-920.

121. Ingelsson M, Fukumoto H, Newell KL, et al. Early Abeta accumulation and progressive synaptic loss, gliosis, and tangle formation in AD brain. Neurology. 2004;62:925-931. 
122. Nordberg A. Amyloid plaque imaging in vivo: current achievement and future prospects. Eur J Nucl Med Mol Imaging. 2008;35(suppl 1):S46-S50.

123. Forsberg A, Engler H, Almkvist O, et al. PET imaging of amyloid deposition in patients with mild cognitive impairment. Neurobiol Aging. 2008;29:1456-1465.

124. Jack CR Jr, Lowe VJ, Weigand SD, et al Serial PIB and MRI in normal, mild cognitive impairment and Alzheimer's disease: implications for sequence of pathological events in Alzheimer's disease. Brain. 2009;132:1355-1365.

125. Scheinin NM, Aalto S, Koikkalainen J, et al. Follow-up of $\left[{ }^{11} \mathrm{C}\right] \mathrm{PIB}$ uptake and brain volume in patients with Alzheimer disease and controls. Neurology. 2009;73:1186-1192.

126. Kadir A, Almkvist O, Forsberg A, et al. Dynamic changes in PET amyloid and FDG imaging at different stages of Alzheimer's disease. Neurobiol Aging. 2010. In press.

127. Forsberg A, Engler H, Almkvist O, et al. PET imaging of amyloid deposition in patients with mild cognitive impairment. Neurobiol Aging. 2002008:1456-1465.

128. Kemppainen NM, Aalto S, Wilson IA, et al. PET amyloid ligand $\left[{ }^{11} \mathrm{C}\right] \mathrm{PIB}$ uptake is increased in mild cognitive impairment. Neurology. 2007;68:1603-1606.

129. Rowe $\mathrm{CC}, \mathrm{Ng} \mathrm{S}$, Ackermann U, et al. Imaging beta-amyloid burden in aging and dementia. Neurology. 2007;68:1718-1725.

130. Okello A, Koivunen J, Edison P, et al. Conversion of amyloid positive and negative MCI to AD over 3 years: an ${ }^{11}$ C-PIB PET study. Neurology. 2009; 73:754-760.

131. Wolk DA, Price JC, Saxton JA, et al. Amyloid imaging in mild cognitive impairment subtypes. Ann Neurol. 2009;65:557-568.

132. Klunk WE, Price JC, Mathis CA, et al. Amyloid deposition begins in the striatum of presenilin-1 mutation carriers from two unrelated pedigrees. J Neurosci. 2007;27:6174-6184.

133. Remes AM, Laru L, Tuominen $\mathrm{H}$, et al. Carbon 11-labeled Pittsburgh compound B positron emission tomographic amyloid imaging in patients with APP locus duplication. Arch Neurol. 2008;65:540-544.

134. Koivunen J, Verkkoniemi A, Aalto S, et al. PET amyloid ligand $\left[{ }^{11} \mathrm{C}\right] \mathrm{PIB}$ uptake shows predominantly striatal increase in variant Alzheimer's disease. Brain. 2008;131:1845-1853.

135. Ng S, Villemagne VL, Berlangieri S, et al. Visual assessment versus quantitative assessment of ${ }^{11} \mathrm{C}$-PIB PET and ${ }^{18} \mathrm{~F}$-FDG PET for detection of Alzheimer's disease. J Nucl Med. 2007;48:547-552.

136. Edison P, Archer HA, Hinz R, et al. Amyloid, hypometabolism, and cognition in Alzheimer disease: an $\left[{ }^{11} \mathrm{C}\right] \mathrm{PIB}$ and $\left[{ }^{18} \mathrm{~F}\right] \mathrm{FDG}$ PET study. Neurology. 2007;68:501-508

137. Pike KE, Savage G, Villemagne VL, et al. Beta-amyloid imaging and memory in non-demented individuals: evidence for preclinical Alzheimer's disease. Brain. 2007;130:2837-2844.

138. Lowe VJ, Kemp BJ, Jack CR Jr, et al. Comparison of ${ }^{18} \mathrm{~F}-\mathrm{FDG}$ and PiB PET in cognitive impairment. J Nucl Med. 2009;50:878-886.

139. Fagan AM, Mintun MA, Mach RH, et al. Inverse relation between in vivo amyloid imaging load and cerebrospinal fluid Abeta42 in humans. Ann Neurol. 2006;59:512-519.

140. Forsberg A, Almkvist O, Engler H, Wall A, Langstrom B, Nordberg A. High PIB Retention in Alzheimer's disease is an early event with complex relationship with CSF biomarkers and functional parameters. Curr Alzheimer Res. 2010;7:56-66.

141. Grimmer T, Henriksen G, Wester HJ, et al. Clinical severity of Alzheimer's disease is associated with PIB uptake in PET. Neurobiol Aging. 2009;30:1902-1909.

142. Mintun MA, Larossa GN, Sheline YI, et al. $\left[{ }^{11} \mathrm{C}\right] \mathrm{PIB}$ in a nondemented population: potential antecedent marker of Alzheimer disease. Neurology. 2006;67:446-452

143. Villemagne VL, Pike KE, Darby D, et al. Abeta deposits in older non-demented individuals with cognitive decline are indicative of preclinical Alzheimer's disease. Neuropsychologia. 2008;46:1688-1697.
144. Aizenstein HJ, Nebes RD, Saxton JA, et al. Frequent amyloid deposition without significant cognitive impairment among the elderly. Arch Neurol. 2008;65:1509-1517.

145. Villemagne VL, Fodero-Tavoletti MT, Pike KE, Cappai R, Masters CL, Rowe CC. The ART of loss: Abeta imaging in the evaluation of Alzheimer's disease and other dementias. Mol Neurobiol. 2008;38:1-15.

146. Sojkova J, Beason-Held L, Zhou Y, et al. Longitudinal cerebral blood flow and amyloid deposition: an emerging pattern? J Nucl Med. 2008;49:1465-1471.

147. Morris JC, Roe CM, Grant EA, et al. Pittsburgh compound B imaging and prediction of progression from cognitive normality to symptomatic Alzheimer disease. Arch Neurol. 2009;66:1469-1475.

148. Engler H, Santillo AF, Wang SX, et al. In vivo amyloid imaging with PET in frontotemporal dementia. Eur J Nucl Med Mol Imaging. 2008;35:100-106.

149. Johansson A, Savitcheva I, Forsberg A, et al. [ $\left.{ }^{11} \mathrm{C}\right]-\mathrm{PIB}$ imaging in patients with Parkinson's disease: preliminary results. Parkinsonism Relat Disord. 2008;14: 345-347.

150. Maetzler W, Reimold M, Liepelt I, et al. $\left[{ }^{11} \mathrm{C}\right] \mathrm{PIB}$ binding in Parkinson's disease dementia. Neuroimage. 2008;39:1027-1033.

151. Edison P, Rowe CC, Rinne JO, et al. Amyloid load in Parkinson's disease dementia and Lewy body dementia measured with $\left[{ }^{11} \mathrm{C}\right] \mathrm{PIB}$ positron emission tomography. J Neurol Neurosurg Psychiatry. 2008;79:1331-1338.

152. Gomperts SN, Rentz DM, Moran E, et al. Imaging amyloid deposition in Lewy body diseases. Neurology. 2008;71:903-910.

153. Fodero-Tavoletti MT, Smith DP, McLean CA, et al. In vitro characterization of Pittsburgh compound-B binding to Lewy bodies. J Neurosci. 2007;27:1036510371 .

154. Burack MA, Hartlein J, Flores HP, Taylor-Reinwald L, Perlmutter JS, Cairns NJ. In vivo amyloid imaging in autopsy-confirmed Parkinson disease with dementia. Neurology. 2010;74:77-84.

155. Bacskai BJ, Frosch MP, Freeman SH, et al. Molecular imaging with Pittsburgh compound B confirmed at autopsy: a case report. Arch Neurol. 2007;64: $431-434$.

156. Johnson KA, Gregas M, Becker JA, et al. Imaging of amyloid burden and distribution in cerebral amyloid angiopathy. Ann Neurol. 2007;62:229-234.

157. Cagnin A, Brooks DJ, Kennedy AM, et al. In-vivo measurement of activated microglia in dementia. Lancet. 2001;358:461-467.

158. Edison P, Archer HA, Gerhard A, et al. Microglia, amyloid, and cognition in Alzheimer's disease: an $\left[{ }^{11} \mathrm{C}\right](\mathrm{R}) \mathrm{PK} 11195-\mathrm{PET}$ and $\left[{ }^{11} \mathrm{C}\right] \mathrm{PIB}-\mathrm{PET}$ study. Neurobiol Dis. 2008;32:412-419.

159. Tomasi G, Edison P, Bertoldo A, et al. Novel reference region model reveals increased microglial and reduced vascular binding of ${ }^{11} \mathrm{C}-(\mathrm{R})-\mathrm{PK} 11195$ in patients with Alzheimer's disease. J Nucl Med. 2008;49:1249-1256.

160. Yasuno F, Ota M, Kosaka J, et al. Increased binding of peripheral benzodiazepine receptor in Alzheimer's disease measured by positron emission tomography with [ ${ }^{11}$ C]DAA1106. Biol Psychiatry. 2008;64:835-841.

161. Gerhard A, Pavese N, Hotton G, et al. In vivo imaging of microglial activation with $\left[{ }^{11} \mathrm{C}\right](\mathrm{R})-\mathrm{PK} 11195$ PET in idiopathic Parkinson's disease. Neurobiol Dis. 2006;21:404-412.

162. Ouchi Y, Yoshikawa E, Sekine Y, et al. Microglial activation and dopamine terminal loss in early Parkinson's disease. Ann Neurol. 2005;57:168-175.

163. Cagnin A, Rossor M, Sampson EL, Mackinnon T, Banati RB. In vivo detection of microglial activation in frontotemporal dementia. Ann Neurol. 2004;56: 894-897.

164. Pavese N, Gerhard A, Tai YF, et al. Microglial activation correlates with severity in Huntington disease: a clinical and PET study. Neurology. 2006;66: 1638-1643.

165. Engler H, Lundberg PO, Ekbom K, et al. Multitracer study with positron emission tomography in Creutzfeldt-Jakob disease. Eur J Nucl Med Mol Imaging. 2003;30:85-95. 